OPEN ACCESS

Edited by:

Oliver Wirths,

University Medical Center Göttingen,

Germany

Reviewed by:

Ulf Andreasson,

Sahlgrenska University Hospital,

Sweden

Alessandro Martorana, University of Rome Tor Vergata, Italy

${ }^{*}$ Correspondence:

Taher Darreh-Shori taher.darreh-shori@ki.se

Received: 21 February 2019 Accepted: 03 July 2019 Published: 31 July 2019

Citation:

Lana E, Gellerbring A, Jung $S$,

Nordberg A, Unger Lithner $C$ and Darreh-Shori T (2019) Homomeric and Heteromeric $A \beta$ Species Exist in Human Brain and CSF Regardless of

Alzheimer's Disease Status and

Risk Genotype.

Front. Mol. Neurosci. 12:176. doi: 10.3389/fnmol.2019.00176

\section{Homomeric and Heteromeric $A \beta$ Species Exist in Human Brain and CSF Regardless of Alzheimer's Disease Status and Risk Genotype}

\author{
Erica Lana ${ }^{1}$, Anna Gellerbring ${ }^{1}$, Sabrina Jung ${ }^{1}$, Agneta Nordberg ${ }^{1,2}$, Christina Unger \\ Lithner $^{1}$ and Taher Darreh-Shori ${ }^{1 *}$
}

\begin{abstract}
${ }^{1}$ Department of Neurobiology, Care Sciences and Society, Division of Clinical Geriatrics, Center for Alzheimer Research, Karolinska Institutet (KI), Stockholm, Sweden, ${ }^{2}$ Theme Aging, The Aging Brain, Karolinska University Hospital, Stockholm, Sweden
\end{abstract}

Background: A fundamental question in Alzheimer's disease (AD) is whether amyloid- $\beta$ $(A \beta)$ peptides and their deposition in the brain signify a direct pathological role or they are mere outcome of the disease pathophysiological events affecting neuronal function. It is therefore important to decipher their physiological role in the brain. So far, the overwhelming focus has been on the potential toxicity of $A \beta$, often studied outside the crucial AD characteristics, i.e.: (i) the slow, decades-long disease progression that precedes clinical symptoms; (ii) the link to apolipoprotein-E $\varepsilon 4$ allele as major risk factor; (iii) the selective early degeneration of cholinergic neurons. Previous studies, in vitro and cerebrospinal fluid (CSF) only, indicated one possible native function of $A \beta$ peptides is the allosteric modulation of acetylcholine homeostasis, via molecular interactions between $A \beta$, apolipoprotein- $E$, and the acetylcholine-degrading enzymes, cholinesterases, resulting in the formation of acetylcholine-hydrolyzing complexes (BABACs).

Methods: Here, by combining sucrose-density gradient fractionation of post-mortem brains and in-house developed sensitive ELISA assays on the obtained fractions, we investigated the presence, levels and molecular interactions between $A \beta$, apolipoprotein-E and cholinesterases for the first time in brain tissues. We examined three distinct brain regions of Alzheimer and non-demented subjects, plus a large number of Alzheimer CSF samples.

Results: We report that both monomeric and oligomeric (homomeric and heteromeric) forms of $A \beta$ peptides are present in the brain of Alzheimer and non-demented individuals. Heteromeric $A \beta$ was found in stable complexes with apolipoprotein- $E$ and/or cholinesterases, irrespective of $A P O E$ genotype or disease status, arguing in favor

\footnotetext{
Abbreviations: A $\beta$, Amyloid- $\beta$; ACh, Acetylcholine; AChE, Acetylcholinesterase; AD, Alzheimer's Disease; APP, Amyloid precursor protein; APOE, Apolipoprotein-E gene; APOE4, $\varepsilon 4$ allele of APOE gene; BuChE, Butyrylcholinesterase; BCHE-K, $\mathrm{K}$ variant of BCHE gene; $\mathrm{BA} \beta \mathrm{ACs}$, BuChE/AChE-A $\beta$-ApoE complexes; ChEs, Cholinesterases; CSF, Cerebrospinal fluid; ELISA, Enzyme-Linked-Immunosorbent Assay; MCI, Mild cognitive impairment; MFG, Medial frontal gyrus; Mw, Molecular weight; NBB, Netherlands Brain Bank; PET, Positron emission tomography; SCD, Subjective cognitive decline; SDG, Sucrose density gradient; SPG, Superior parietal gyrus; STG, Superior temporal gyrus; WB, Western-blot.
} 
of a physiological dynamic formation and function for these complexes in the brain. The patterns and molecular sizes of the detected soluble $A \beta$ forms were closely matched between CSF and brain samples. This evinces that the detected $A \beta$-apolipoprotein- $E$ complexes and BABACs in CSF most likely originate from the interstitial fluids of the brain.

Conclusions: In conclusion, both light homomeric $A \beta$ oligomers and heteromeric $A \beta-A p o E$ and BA $\beta A C s$ are present and readily detectable in the brain, regardless of disease status and APOE4 genotype. Deeper knowledge of the physiological function of $A \beta$ is crucial for better understanding the early pathological events that decades later lead to manifestation of AD.

Keywords: Alzheimer's disease, homomeric and heteromeric amyloid- $\beta$, apolipoprotein E, cholinesterases, cholinergic signaling

\section{BACKGROUND}

Alzheimer's disease (AD) is the most common form of dementia in the elderly population. One of the major pathological hallmarks of the $\mathrm{AD}$ brain is the presence of plaques composed of amyloid-beta $(A \beta)$ fibrils. The $A \beta$ peptides and several other fragments are generated through a highly sophisticated and complex enzymatic cleavage of amyloid precursor protein (APP), which occurs up-to-date at four different sites $(\alpha, \beta, \eta$ and $\gamma$; Willem et al., 2015). The complexity of the APP processing increases even more if one includes the mechanisms involved in the cellular trafficking of APP (O'Brien and Wong, 2011) to and from the cell membranes, the action-potential synchronized synaptic release of $A \beta$ peptides (Cirrito et al., 2005), and the diurnal cycle for $A \beta$ levels in the interstitial fluids in the brain (Kang et al., 2009).

A fundamental question is hence to decipher the physiological function of these peptides in the brain. This, in turn, should allow us to decode how and when the $\mathrm{A} \beta$ peptides and/or their effector units turn pathological with regards to the basic neuronal functions and the brain microenvironment.

Yet, the overwhelming focus of the research in the field appears to be on the potential toxicity and pathogenicity of the $\mathrm{A} \beta$ peptides, and very few studies are done on deciphering their native biological functions (Fogel et al., 2014; Kumar et al., 2016). During the last decades, the $A \beta$ toxicity paradigm has been shifted from focusing on $A \beta$ fibrils and plaques to the soluble $\mathrm{A} \beta$ oligomers and protofibers (Klein et al., 2001). In particular, soluble $A \beta$ oligomers are currently regarded as the culprit for synaptic pathologies and memory deficits observed in AD (Klein, 2002; Walsh and Selkoe, 2004).

In addition, the toxicity of $\mathrm{A} \beta$ peptides has been most often studied outside the context and the crucial characteristics of $A D$, such as: (i) the very slow disease progression that requires several decades to cause discernable pathological manifestations; (ii) its link to advanced age and to the $\varepsilon 4$ allele of apolipoprotein-E $(A P O E)$ gene, as major risk factors; and (iii) the selective and early degeneration of the central cholinergic neurons.

Furthermore, the main utilized technique for showing the existence of the $A \beta$ oligomers has been Western-blotting, which is fundamentally unsuitable for such a purpose. Another prevailing presumption is that $A \beta$ oligomers are homomeric, i.e., the complexes consist only of $\mathrm{A} \beta$ peptides (Lambert et al., 2001; Klein, 2002; Gong et al., 2003; Georganopoulou et al., 2005; Esparza et al., 2013; Yang et al., 2013; Cohen et al., 2015). Therefore, the absolute majority of studies (on cell cultures and/or animal tissues) have used $\mathrm{A} \beta$ oligomers that are prepared from $\mathrm{A} \beta 40$ or $\mathrm{A} \beta 42$, and few also a mixture of $A \beta 40 / 42$ peptides. This is despite the results of numerous studies on postmortem brain tissues, reporting that $\mathrm{A} \beta$ deposits are most often accompanied by various other proteins. ApoE protein, and the acetylcholine-degrading enzymes, acetylcholinesterase (AChE) and butyrylcholinesterase (BuChE) are the most prominent examples (Geula et al., 1994; Rees et al., 2003). Reports also exist concerning such molecular interactions between $\mathrm{A} \beta$ peptides and ApoE, ApoJ and/or $\mathrm{AChE}$ and $\mathrm{BuChE}$ proteins in vitro and in cerebrospinal fluid (CSF) samples (Ghiso et al., 1993; Strittmatter et al., 1993a,b; Diamant et al., 2006; Darreh-Shori et al., 2011a,b; Kumar et al., 2016). Few studies have also reported possible consequences of such heteromeric molecular interactions, for instance that AChE accelerates (Rees et al., 2003), while BuChE delays A $\beta$ fibrillization (Diamant et al., 2006; Podoly et al., 2008). There is also additional in vivo evidence from positron emission tomography (PET) imaging studies that support albeit indirectly the heteromeric molecular interactions between ApoE and/or BuChE and $\mathrm{A} \beta$, with an increased $\mathrm{A} \beta$ aggregation/deposit as one of the consequences (Saunders et al., 1993; Schmechel et al., 1993; Kay et al., 2003; Ramanan et al., 2014).

It is also important to recognize that the observations in post-mortem brain as well as the PET studies most likely reflect the endpoint outcome of a slow and subtle long-term interaction between these proteins and $\mathrm{A} \beta$ peptides rather than a fast phenomenon. Indeed, it is now well-established that when the clinical symptoms become evident the pathological events have been ongoing for several decades. An unexpected observation reported from this laboratory emphasizes this need for a proper understanding of the temporal and the differential sequence of outcomes of the interaction of other macromolecules 
with $\mathrm{A} \beta$ peptides. While there are no doubts that APOE4 genotype and $\mathrm{ApoE} \varepsilon 4$ isoprotein are associated with the higher amount of fibrillar forms of $\mathrm{A} \beta$ deposits in the $\mathrm{AD}$ brain (Saunders et al., 1993; Schmechel et al., 1993; Kay et al., 2003; Ramanan et al., 2014), we have found that ApoE, in particular the $\varepsilon 4$ isoprotein, at physiological concentrations is one of the strongest endogenous anti- $\mathrm{A} \beta$ fibrillization agents (Kumar et al., 2016). At the highest tested concentration, which corresponded to the CSF ApoE levels found in APOE4 homozygotes, ApoE protein prevented $A \beta$ fibrillization for at least $65 \mathrm{~h}$, although the tested $A \beta$ concentration was as high as $20 \mu \mathrm{M}$ (Kumar et al., 2016). Thus, how and when such a strong anti- $\mathrm{A} \beta$ fibrillization activity of ApoE protein changes into an $A \beta$ fibrillization-promoting activity is important to be carefully elucidated.

Overall, all these studies, regardless of being conducted on highly purified proteins, extracts from cell cultures and/or CSF samples confirm one phenomenon beyond any doubt: that a direct molecular interaction occurs between $A \beta$ peptides and ApoE and/or the cholinesterases (AChE and BuChE; Ghiso et al., 1993; Saunders et al., 1993; Schmechel et al., 1993; Strittmatter et al., 1993a,b; Wisniewski et al., 1993; Geula et al., 1994; Mesulam and Geula, 1994; Rees et al., 2003; Diamant et al., 2006; Podoly et al., 2008; Darreh-Shori et al., 2011a,b; Ramanan et al., 2014; Kumar et al., 2016).

Although we have examined, both in vitro and in CSF, the formation of heteromeric soluble $\mathrm{A} \beta$-ApoE and BuChE/AChE$A \beta-A p o E$ (termed as BA $\beta A C s$ ), no study is yet available on the formation and/or sources of these soluble heteromeric $A \beta$ complexes in the brain. Here, we investigated the presence of these complexes in the brain homogenates $(\mathrm{BH})$ prepared from frontal, parietal and temporal cortices of the brain of a group of $\mathrm{AD}$ and control cases, and also compared the findings with those observed in the CSF of $\mathrm{AD}$ patients, in particular in relation to the APOE4 genotype.

The results indicate that both light homomeric $A \beta$ oligomers $(<48 \mathrm{kDa})$ and heteromeric $\mathrm{A} \beta-\mathrm{ApoE}$ and $\mathrm{BA} \beta \mathrm{ACs}$ are present and readily detectable in the brain, regardless of the disease status and APOE4 genotype. In $\mathrm{AD}, \mathrm{BA} \beta \mathrm{ACs}$ were abnormally hyperactive in both CSF and brain and accompanied by higher ApoE levels. Thus, the current report provides new evidence that both homomeric $A \beta$ and heteromeric complexes of $\mathrm{A} \beta$ with $\mathrm{ApoE}$ and cholinesterases occur naturally in the brain, and emphasizes the need for further deciphering their possible biological function in the human brain, as well as their possible pathological alterations during the course of AD.

\section{MATERIALS AND METHODS}

\section{CSF Pooled Samples and Post-mortem Brain Tissue Homogenates}

The CSF samples were prepared as previously described (Vijayaraghavan et al., 2013). Briefly, nine pooled CSF samples obtained from 179 patients with the clinical diagnosis of mild-tomoderate $\mathrm{AD}$ with defined $A P O E$ and $B C H E-K$ genotypes were prepared by pooling equal volumes of at least three independent samples with identical genotypes. All samples were collected prior to any cholinesterase inhibitor treatment.

The following nine genotype combinations of pooled samples were prepared:
A $\quad\left(\mathrm{APOE}^{\varepsilon 44} / \mathrm{BCHE}^{W W}\right)$;
B $\left(\mathrm{APOE}^{\varepsilon 44} / \mathrm{BCHE}^{K K}\right)$;
C $\left(\mathrm{APOE}^{\varepsilon 44} / \mathrm{BCHE}^{W K}\right)$;
D $\left(\mathrm{APOE}^{843} / \mathrm{BCHE}^{W W}\right)$;
E $\quad\left(\mathrm{APOE}^{\varepsilon 43} / \mathrm{BCHE}^{K K}\right)$;
F $\quad\left(\mathrm{APOE}^{\varepsilon 43} / \mathrm{BCHE}^{W K}\right)$;
G $\left(\mathrm{APOE}^{\varepsilon 33} / \mathrm{BCHE}^{W W}\right)$;
I $\left(\mathrm{APOE}^{\varepsilon 33} / \mathrm{BCHE}^{W K}\right)$.
H $\left(\mathrm{APOE}^{\varepsilon 33} / \mathrm{BCHE}^{K K}\right)$;

Cortical brain tissues were from medial frontal gyrus (MFG), superior temporal gyrus (STG) and superior parietal gyrus (SPG) of AD patients $(n=6$, mean age $80.5 \pm 8.5$, Braak $5-6$, post-mortem time $4.98 \pm 0.45 \mathrm{~h})$ and of age-matched non-demented controls ( $n=6$, mean age $80.2 \pm 7.9$, Braak $1-2$, post-mortem time $7.72 \pm 1.6 \mathrm{~h}$ ), Table 1 . These regions are known to have pathological changes in $\mathrm{AD}$ (Connor et al., 1993; Nicoll et al., 2003; Neufang et al., 2011).

The brain tissues were sequentially homogenized in three different buffers in order to isolate soluble $(s-)$, ionic $(i-)$, and membrane-bound $(\mathrm{m}-)$ proteins, as described below. The whole procedure was done at $4^{\circ} \mathrm{C}$, excepted when otherwise indicated. The tissue was homogenized in a $15 \times$ volume of ice-cold

TABLE 1 | Demographic characteristics for the post-mortem brain tissues.

\begin{tabular}{|c|c|c|c|c|c|c|c|}
\hline NBB Sample number & Disease status & Brain region & Duration of disease (y) & Braak stage & PMD (h) & APOE genotype & BCHE genotype \\
\hline 1995-054 & Ctrl & MFG, SPG, STG & - & I & 9.2 & $\varepsilon 3 / \varepsilon 3$ & $\mathrm{~K}+\mathrm{l}-$ \\
\hline 1996-085 & Ctrl & MFG, SPG, STG & - & 1 & 9.0 & $\varepsilon 3 / \varepsilon 3$ & $\mathrm{~K}-/-$ \\
\hline 2008-027 & Ctrl & MFG, SPG, STG & - & I & 7.0 & $\varepsilon 4 / \varepsilon 3$ & $\mathrm{~K}-/-$ \\
\hline 2008-032 & Ctrl & MFG, SPG, STG & - & $\|$ & 8.9 & $\varepsilon 4 / \varepsilon 3$ & $\mathrm{~K}-/-$ \\
\hline 2008-054 & Ctrl & MFG, SPG, STG & - & 1 & 7.0 & $\varepsilon 4 / \varepsilon 3$ & $\mathrm{~K}+1-$ \\
\hline 2009-005 & Ctrl & MFG, SPG, STG & - & I & 5.2 & $\varepsilon 2 / \varepsilon 3$ & $\mathrm{~K}-/-$ \\
\hline 2004-068 & $A D$ & MFG, SPG, STG & 5 & VI & 6.5 & $\varepsilon 4 / \varepsilon 4$ & $\mathrm{~K}-/-$ \\
\hline 2005-040 & $A D$ & MFG, SPG, STG & 9 & VI & 5.0 & $\varepsilon 4 / \varepsilon 3$ & $\mathrm{~K}-\mathrm{I}-$ \\
\hline 2006-059 & $A D$ & MFG, SPG, STG & 11 & VI & 3.75 & $\varepsilon 4 / \varepsilon 3$ & $\mathrm{~K}+\mathrm{l}-$ \\
\hline 2007-052 & $A D$ & MFG, SPG, STG & 8 & V & 4.25 & $\varepsilon 4 / \varepsilon 3$ & $\mathrm{~K}-\mathrm{I}-$ \\
\hline 2007-073 & $A D$ & MFG, SPG, STG & 12 & V & 6.1 & $\varepsilon 3 / \varepsilon 3$ & $\mathrm{~K}-1-$ \\
\hline 2008-004 & $A D$ & MFG, SPG, STG & 6 & VI & 4.3 & $\varepsilon 4 / \varepsilon 3$ & $\mathrm{~K}-/-$ \\
\hline
\end{tabular}

Gender was equally distributed between and within the groups. The mean age was 80 years and ranged 71-92 among the controls and 69-91 among the AD group. Ctrl, Non-demented control; AD, Alzheimer's disease patient; NBB, Netherlands Brain Bank; MFG, medial frontal gyrus; SPG, superior parietal gyrus; STG, superior temporal gyrus; $P M D$, post-mortem delay; $y$, years; $h$, hours. 
buffer-I (50 mM Na/K-phosphate buffer, $\mathrm{pH}$ 7.4, prepared from $33 \mathrm{mM} \mathrm{Na} 2 \mathrm{H}_{2} \mathrm{PO}_{4}\left(2 \mathrm{H}_{2} \mathrm{O}\right), 17 \mathrm{mM} \mathrm{KH} \mathrm{PO}_{4}, 2 \mathrm{mM}$ EDTA), centrifuged at $35,000 \mathrm{~g}$ for $30 \mathrm{~min}$ at $4^{\circ} \mathrm{C}$, and the supernatant was carefully transferred to a new tube, and was designated as the soluble (s-) brain protein extract. Then, the tissue pellet was rehomogenized further in $15 \times$ volume of high salt containing buffer-II (buffer-I $+500 \mathrm{mM} \mathrm{NaCl}$ ) and centrifuged as before. The supernatant was transferred to another tube and was designated as the ionic ( $i$-) brain protein extract. The remaining pellet was rehomogenized once more in $15 \times$ volume of buffer-III (buffer II $+0.6 \%$ (v/v) Triton X-100) and centrifuged as before, and the supernatant was transferred to another tube and was designated as the membrane-bound ( $m-)$ brain protein extract.

The total protein concentration was quantified in all the obtained brain extracts by the $D C^{\mathrm{TM}}$ Protein colorimetric Assay (Bio-Rad) according to the manufacturer instructions. Serial dilutions of BSA solutions, ranging between $8 \mathrm{mg} / \mathrm{ml}$ and $0.0625 \mathrm{mg} / \mathrm{ml}$, were prepared in the different extraction buffers and used as standard concentrations for quantification of total proteins in the corresponding brain extracts.

\section{Genotyping of Brain Tissue Samples}

Pieces of frozen brain tissue with an average weight of $20 \mathrm{mg}$ were cut from the SPG brain region of each individual and the DNA was extracted with a QIAamp DNA Mini Kit (51304, Qiagen) according to the manufacturer's protocol. Genotyping analyses for APOE were performed on the extracted DNA using the TaqMan ${ }^{\circledR}$ GTXpress ${ }^{\text {TM }}$ Master Mix (4403311, Applied Biosystems) and the TaqMan ${ }^{\circledR}$ genotyping assays C_3084793_20 and C_904973_10, corresponding to $A P O E$ SNPs rs429358 (APOE \&4) and rs7412 (APOE $\varepsilon 2)$ respectively, according to the manufacturer's instruction, on a StepOne Plus ${ }^{\mathrm{TM}}$ thermal cycler (Applied Biosystems). For $B C H E$ genotyping, the rs1803274 SNP was analyzed (assay ID: C_27479669_20), which corresponds to the k-variant of BCHE.

\section{Sucrose Gradient Sedimentation Analysis}

Sucrose density gradient (SDG) analysis was used to investigate the presence of homomeric and heteromeric forms of $A \beta$ peptides in the CSF and the brain homogenates. The potential interacting proteins that were assessed were BuChE, AChE, and ApoE proteins, which were previously shown to form stable complexes with A $\beta$ peptides (Kumar et al., 2016). The SDG procedure for pooled CSF samples was described in detail before (Kumar et al., 2016). The SDG procedure for the brain homogenates was the same with minor modifications. Briefly, equal volumes of each brain homogenate (i.e., the soluble, ionic and membrane-bound extracts) were pooled together for each brain region (SPG, MFG, or STG) and for each subject ( $\mathrm{six} \mathrm{AD}$ and six controls). In total 36 pooled brain homogenate samples were examined. Each pooled brain homogenate sample $(0.3 \mathrm{~mL}$ of sample) was then applied on the top of a transparent Ultra-Clear ultracentrifuge tube (UC, Ultra-Clear ${ }^{\mathrm{TM}}$ tube, Cat No. 344059, Beckman, Brea, CA, USA), containing $10 \mathrm{~mL}$ of sucrose gradient. In comparison, the amount of the applied pooled CSF samples was $0.5 \mathrm{~mL}$.
The gradient was prepared in advance by adding first $5 \mathrm{~mL}$ of a $5 \%$ sucrose solution (wt/vol) in TBS- $\mathrm{MgCl}_{2}(10 \mathrm{mM}$ Tris- $\mathrm{HCl}, \mathrm{pH} 7.4,0.9 \% \mathrm{NaCl}$ and $50 \mathrm{mM} \mathrm{MgCl}_{2}$ ) to the UC tube. Then $5 \mathrm{~mL}$ of a $20 \%$ sucrose solution were added by inserting the tip of a Pasteur pipette into the bottom of the UC tube and pipetting the sucrose solution into the upper end of the Pasteur pipette. After sample addition, the UC tube was then capped, rolled on a 45 degree angled surface, and brought to vertical position in a tube holder. The tubes were then subjected to ultracentrifugation for $18 \mathrm{~h}$ at $4^{\circ} \mathrm{C}$ at $165,000 \mathrm{~g}(36,600 \mathrm{rpm})$ in a Beckman Ultracentrifuge (XL100, rotor SW $41 \mathrm{Ti}$ ). Approximately 50 fractions were then collected from the bottom of each tube into a 96-well lowprotein-binding microtiter plate that was pretreated with TBS solution containing $0.2 \%$ Tween-20 to reduce protein loss from the fractions.

Enzymes of known sedimentation coefficient (S) - bovine liver catalase $(11.4 \mathrm{~S} ; \sim 250 \mathrm{kDa}$, Sigma) and calf intestinal alkaline phosphatase (6.1 S; $\sim 140 \mathrm{kDa}$, Sigma)-were used in the gradients to estimate the sedimentation coefficient (S) for the individual SDG fractions, using the following formula: $\mathrm{S}_{\mathrm{F}}=(\mathrm{Ft}$ - Fn $) /\left[\left(\mathrm{Ft}-\mathrm{F}_{\mathrm{i}}\right)^{*} \mathrm{~S}_{\mathrm{i}}\right]$ where $\mathrm{S}_{\mathrm{F}}$ is the sedimentation coefficient of a specific fraction, $\mathrm{Ft}$ is the total number of fractions from each SDG tube, Fn is the number of the specific fraction of interest, $S_{i}$ and $F_{i}$ are the known sedimentation coefficient and the fraction number showing the highest signal for the internal standard protein, respectively.

The estimated $\mathrm{S}$ values were then used to estimate the relative molecular weight for the measured proteins and their complexes detected in the fractions $\left(\mathrm{Mw}_{\mathrm{F}}\right)$, using the following formula, known as Svedberg equation: $\mathrm{Mw}_{\mathrm{F}}=\left(\mathrm{Mw}_{\mathrm{i}} \times \mathrm{S}_{\mathrm{F}}^{2}\right) / \mathrm{S}^{2}{ }_{\mathrm{i}}$ where $\mathrm{Mw}_{\mathrm{i}}$ and $\mathrm{S}_{\mathrm{i}}$ are the known $\mathrm{Mw}$ and $\mathrm{S}$ values for the internal standard protein (for instance $140 \mathrm{kDa}$ and $6.1 \mathrm{~S}$ for calf intestinal alkaline phosphatase).

As previously described (Kumar et al., 2016), we did not observe any molecular interaction between these internal standard proteins and the $\mathrm{A} \beta, \mathrm{AChE}, \mathrm{BChE}$ or $\mathrm{ApoE}$ proteins present in the fractions.

\section{Detection and Measurement of Analytes in the SDG Fractions}

\section{Quantification of the $A \beta_{40}$ and $A \beta_{42}$ Levels}

The relative levels of $A \beta_{40}$ and $A \beta_{42}$ in each collected SDG fraction were measured by an in-house developed sandwich enzyme-linked immunosorbent assay (ELISA). First, a 384-well plate (Nunc MaxiSorp) was coated overnight at $4^{\circ} \mathrm{C}$ with $50 \mu \mathrm{L} /$ well of rabbit polyclonal anti-A $\beta_{40}$ antibody (AB5074P, Millipore, Burlington, MA, USA) or rabbit polyclonal antiA $\beta_{42}$ antibody (AB5078P, Millipore, Burlington, MA, USA). The working solution of the antibodies was prepared at 1:16,000 in coating buffer (100 mM carbonate buffer $\mathrm{pH}$ 9.8: $30 \mathrm{mM}$ $\mathrm{Na}_{2} \mathrm{CO}_{3}, 70 \mathrm{mM} \mathrm{NaHCO}, 0.01 \%$ Thimerosal). After coating, the plate was washed $1 \times 5$ min with TBS and blocked for $1 \mathrm{~h}$ at room temperature (RT) with $75 \mu \mathrm{L} /$ well of blocking buffer $(4 \%$ $\mathrm{wt} / \mathrm{v}$ of BSA in the coating buffer). After $3 \times 5$ min washings with $100 \mu \mathrm{L} /$ well of TBS-T buffer (10 mM TBS, containing 
$0.05 \%$ Tween-20 and $0.01 \% \mathrm{NaN}_{3}$ ), $50 \mu \mathrm{L}$ of standards and undiluted samples were applied to the wells, and the plate was incubated overnight at $4^{\circ} \mathrm{C}$. As standards, a 2-fold dilution series of a pooled brain homogenate sample (soluble fractions only), ranging from $660 \mu \mathrm{g} / \mathrm{mL}$ total protein to $645 \mathrm{ng} / \mathrm{ml}$ (in TBS, containing $0.05 \%$ Triton X-100, 5\% sucrose, and $0.01 \%$ NaN3) was prepared and used to estimate the relative amounts of $A \beta$ in the SDG fractions. The plate was then washed $3 \times 5 \mathrm{~min}$ as before with TBS-T, and incubated for $3 \mathrm{~h}$ at $37^{\circ} \mathrm{C}$ with $50 \mu \mathrm{L} /$ well of working solution of a mouse monoclonal anti$\mathrm{A} \beta_{1-16}$ antibody (SIG-39300, 6E10, Covance; at 1:4,000 dilution in TBS-T buffer, containing $3 \% \mathrm{BSA}$ ). After $3 \times 5$ min washings as before, the plate was incubated for $2 \mathrm{~h}$ at RT with $50 \mu \mathrm{L} /$ well of working solution of a biotin-conjugated goat polyclonal anti-mouse IgG antibody (B6649, Sigma; at 1:10,000 dilution in TBS-T buffer, containing 3\% BSA). The plate was then washed as before and incubated for $2 \mathrm{~h}$ with $50 \mu \mathrm{L} /$ well of a solution containing AP-conjugated streptavidin (11093266910, Roche; 1:5,000 in the TBS-T-BSA buffer). Finally, the plate was washed $4 \times 5 \mathrm{~min}$ with TBS-T, and $1 \times 5 \mathrm{~min}$ with DEA buffer (1 $\mathrm{M}$ diethanolamine buffer, containing $0.5 \mathrm{mM}$ $\mathrm{MgCl}_{2} \bullet 6 \mathrm{H}_{2} \mathrm{O}, 0.01 \% \mathrm{NaN}_{3}, \mathrm{pH} 9.8$ ), and then $50 \mu \mathrm{L}$ of the AP substrate, p-Nitrophenyl-Na2-6 $\mathrm{H}_{2} \mathrm{O}(1 \mathrm{mg} / \mathrm{ml}$ in DEA buffer $)$ were added and the plate was read at $405 \mathrm{~nm}$, and also at $570 \mathrm{~nm}$ (as reference wavelength) by a microplate reader (Infinite M1000, Tecan).

\section{Quantification of ApoE Protein Levels}

The levels of ApoE protein in the SDG fractions and in the unfractionated brain homogenates were assessed by an in-house developed sandwich ELISA as described before (Darreh-Shori et al., 2011b). Briefly, the general steps were as mentioned above for the A $\beta$ ELISA. The capturing antibody was a mouse monoclonal anti-ApoE antibody (MAB A1.4, Sigma; at 1:8,000 dilution in carbonate buffer, $\mathrm{pH}$ 9.8). The 16 standard points were $50 \mu \mathrm{l} /$ well of a 2 -fold serial dilution starting with $2 \mu \mathrm{g} / \mathrm{ml}$ of a purified human ApoE protein (ALP70-50UG, Millipore, Burlington, MA, USA; diluted in $10 \mathrm{mM}$ TBS, containing $0.2 \%$ Tween-20 and $0.01 \% \mathrm{NaN} 3, \mathrm{pH}$ 7.5). The SDG fraction samples or the unfractionated brain homogenate samples were diluted (1:3) in advance in TBS$\mathrm{T}^{0.2 \%}$ buffer and added to the wells $(50 \mu \mathrm{L} /$ well $)$. The detecting antibody was a goat polyclonal anti-ApoE antibody (GAB947, Millipore, Burlington, MA, USA; diluted at 1:3,000 in TBS$\mathrm{T}^{0.05 \%}$, containing $0.5 \% \mathrm{BSA}$ ). The secondary antibody was an alkaline phosphatase-conjugated bovine anti-goat antibody (sc-2353, Santa Cruz; used at 1:2,000 dilution in TBS-T ${ }^{0.05 \%}$, containing $0.5 \%$ BSA). The AP substrate p-Nitrophenyl$\mathrm{Na} 2-6 \mathrm{H}_{2} \mathrm{O}(1 \mathrm{mg} / \mathrm{ml}$ in DEA buffer) was added (50 $\mu \mathrm{l} /$ well $)$ to generate a colorimetric reaction that was read by measuring the absorbance at $405 \mathrm{~nm}$ in a Tecan Infinite M1000 plate reader.

\section{AChE and BuChE Activity Measurements}

Ellman's colorimetric assay was used to determine AChE and $\mathrm{BuChE}$ activities in the brain homogenates and in the pooled CSF samples. Wells containing the sample buffer or just the $\mathrm{A} \beta$ and/or ApoE were used as negative controls. For measuring BuChE activity a master mix (MMB) was freshly prepared and used. MMB contained the BuChE substrate, i.e. butyrylthiocholine iodide (BTC, $5.0 \mathrm{mM}$ final concentration, Sigma), the Ellman's reagent DTNB $(0.4 \mu \mathrm{M}$ final concentration, Sigma) and the selective AChE inhibitor, BW284C51 (0.001 mM final concentration) in sodium potassium phosphate buffer (50 mM, pH 7.4). For AChE activity, the master mix consisted of the substrate, acetylthiocholine iodide (ATC, $0.5 \mathrm{mM}$ final concentration, Sigma) instead of BTC, and the selective BuChE inhibitor, ethopropazine $(0.1 \mathrm{mM}$ final concentration) instead of BW284C51.

In addition to activity measurement, the protein levels of these enzymes in each SDG fraction were determined by ELISA as described before (Darreh-Shori et al., 2006).

\section{Statistical Analyses}

Data are expressed as mean values and standard error of the mean (SEM). Student's $t$-test was used to compare the levels of biomarkers in the AD and control brain extracts.

\section{RESULTS}

\section{Distinct Molecular Forms of $A \beta$ Are Present in Both AD and Control Brains}

$A \beta$ oligomers have been considered as the most toxic forms of $A \beta$ aggregates, we, therefore, investigated their presence in $\mathrm{AD}$ and control brains. To avoid misinterpretation and artifacts we used SDG fractionation of the brain homogenates and analysis of $A \beta$ in the fractions by ELISA.

The results are summarized in Figure 1. A comparison between $A \beta_{40}$ SDG diagrams in control (Figure 1A) and $A D$ brains (Figure 1B), revealed the presence of two light peaks corresponding to a $\mathrm{Mw}$ range of $4-32 \mathrm{kDa}$ (light green shaded area) in both control and AD brains. Similar twin light-Mw peaks were observed in the $\mathrm{A} \beta_{42}$ SDG diagrams (Figures 1C,D). These peaks most likely represent the light homomeric forms of $A \beta$ peptides (monomeric, dimeric, tetrameric and hexa/octameric forms). Noteworthy, the pattern and Mw ranges were very similar between the $\mathrm{AD}$ and control brains.

Another noteworthy observation is that in the $A \beta$ light-peak region the control SDG diagrams suggest that the $4-16 \mathrm{kDa}$ $\mathrm{A} \beta_{40}$ and $\mathrm{A} \beta_{42}$ peaks have higher intensities than the $16-32 \mathrm{kDa}$ $\mathrm{A} \beta_{40}$ or $\mathrm{A} \beta_{42}$ peaks (compare Figures $1 \mathrm{~A}, \mathrm{C}$ ), whilst these peaks have essentially identical intensities in the AD SDG diagrams (Figures 1B,D). In other words, dimeric forms of $A \beta_{40}$ or $A \beta_{42}$ peptides dominate in the control brain, whereas in the $\mathrm{AD}$ brain SDG diagrams the peaks corresponding to the dimeric and tetrameric forms of $\mathrm{A} \beta$ peptides have similar peak intensities (Figures 1A,C vs. Figures 1B,D).

\section{A $\beta$ Peptides Interact With ApoE Protein}

In addition, the $A \beta$ SDG diagrams showed the presence of a triple peak with moderate $\mathrm{Mw}$, ranging between $32 \mathrm{kDa}$ and $128 \mathrm{kDa}$ (Figure 1, light blue shaded area). Using recombinant $A \beta$ peptides, we have previously shown that $A \beta$ interacts with ApoE protein, producing stable soluble $A \beta$-ApoE complexes (Kumar et al., 2016). We, therefore, investigated whether similar 


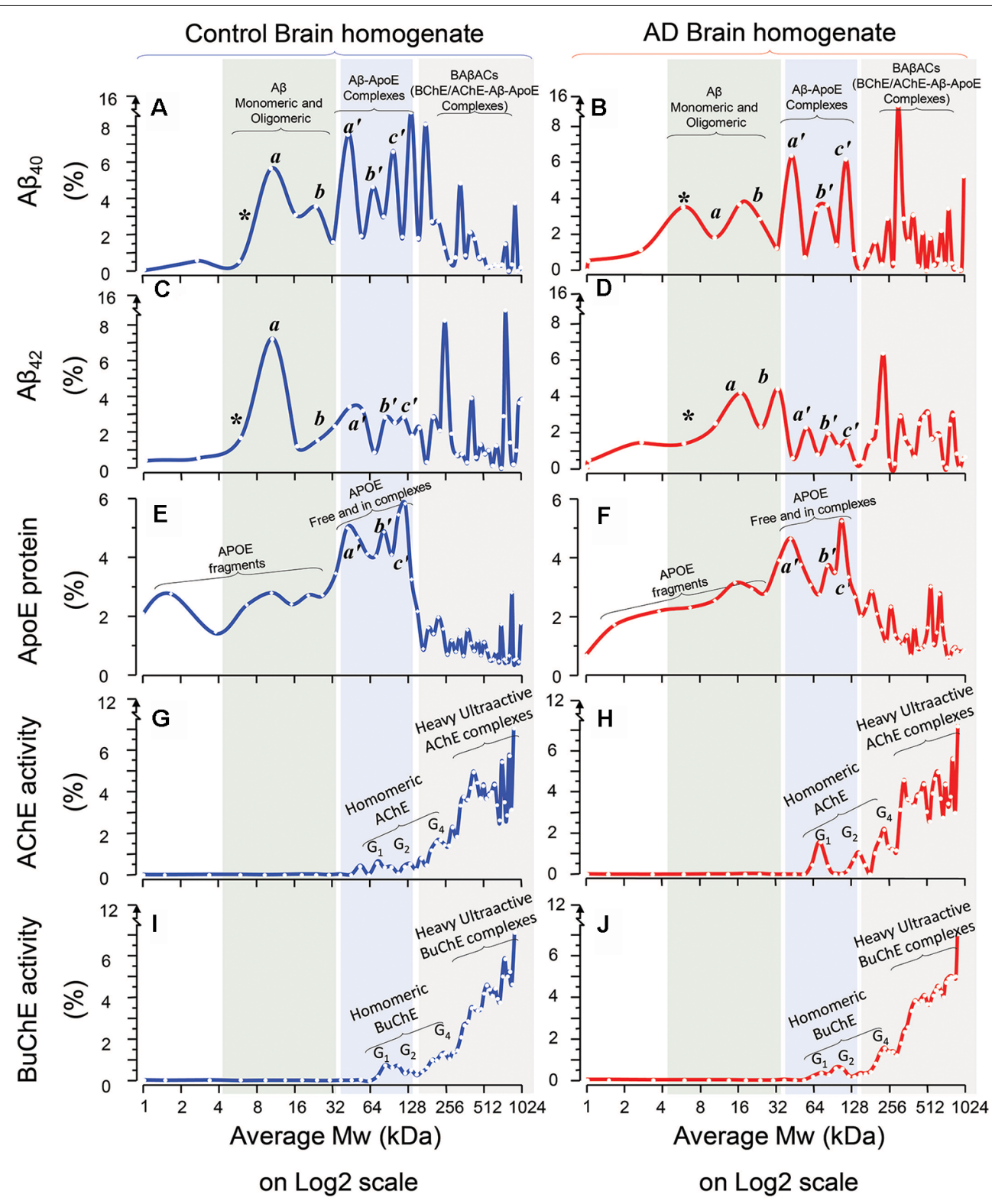

FIGURE 1 | Homomeric and heteromeric forms of Amyloid-beta (AB), Apolipoprotein-E (ApoE) and cholinesterases in Alzheimer's Disease (AD) and non-demented post-mortem brain. Sucrose density gradient (SDG) and ultracentrifugation were used to separate the protein content in the brain homogenates (BH) from a group of $\mathrm{AD}(n=6)$ and non-demented controls $(n=6)$, from three different brain regions, medial frontal gyrus (MFG) and/or superior temporal gyrus (STG) and/or superior parietal gyrus (SPG). Following o/n ultracentrifugation, the content of each SDG tube was fractionated into 50 equal fractions from the bottom of the tubes, and the levels of $A \beta_{1-40}, A \beta_{1-42}$, and ApoE proteins, as well as of Acetylcholinesterase (AChE) and Butyrylcholinesterase (BuChE) activities were measured in all fractions, as further described in the "Materials and Methods" section. The $y$-axis in the SDG spectra indicates the protein level or activity level corresponding to each SDG fraction, represented as \% of the total level of that protein in the SDG gradient. The x-axis shows the log2 scale of estimated molecular weight (Mw) corresponding to each fraction content. Each spectrum is composed of aggregated data from the three examined brain regions. (A-D) The relative levels of $A \beta_{1-40}(\mathbf{A}, \mathbf{B})$ and $A \beta_{1-42}$ (C,D) peptides in the fractions are plotted vs. the corresponding molecular weights (Mw) of the fractions. The peaks indicated as *, a, and b exhibit Mw values that closely correspond to the molecular weight of A $\beta$ monomers $(\sim 4 \mathrm{kDa})$, dimers $(\sim 8 \mathrm{kDa})$ and tetramers or hexamers $(\sim 16-24 \mathrm{kDa})$ respectively (light green shaded areas). The peaks indicated as a', b', and c' exhibit Mw values that closely correspond to the molecular weight of ApoE monomers ( 34 kDa), dimers ( 68 kDa) and ApoE complexes $(\sim 128 \mathrm{kDa}$ ) respectively, which indicates that $\mathrm{A} \beta$ peptides were incorporated into stable $A \beta$-ApoE complexes (the light blue shaded areas). This is confirmed in (E,F), where the levels of ApoE protein are plotted against the Mw values of the fractions. The peaks a', and b' exhibit Mw values that closely correspond to the molecular weight of ApoE monomers ( $\sim 34 \mathrm{kDa})$ and dimers ( 68 kDa) respectively, whereas peak c' $(\sim 128 \mathrm{kDa})$ indicates heavy ApoE complexes with $A \beta$ (light blue shaded areas). In other words, both ApoE and AB SDG spectra indicate that $A \beta$ and ApoE co-sediment and thereby form complexes in the human brain (extracts). (G-J) The relative levels of AChE (G,H) and BuChE (I,J) enzymatic activities in the SDG fractions are plotted against the Mw values of the fractions. The activity peaks indicated as $G_{1}, G_{2}$ and $G_{4}$ exhibit $M w$ values that closely correspond to the expected molecular weight of the monomeric, dimeric and tetrameric globular forms of AChE and BuChE ( 55-70, 110, $250 \mathrm{kDa}$ and 75, 150, $280 \mathrm{kDa}$, respectively). Nonetheless, the most activity-intense peaks show much

(Continued) 


\section{FIGURE 1 | Continued}

heavier Mw than the Mw expected for G4 AChE and/or BuChE. A

comparison of these heaviest peaks in the SDG spectra among all the panels (gray shaded areas in $\mathbf{A}-\mathbf{J}$ ) clearly indicate that these heavy AChE/BuChE molecules co-sediment with certain heavy peaks that contain both $A B$ (A-D) and ApoE (E,F). Thus, the presence of activity-intense AChE and BuChE peaks at higher $\mathrm{Mw}$ fractions ( $>250 \mathrm{kDa}$, gray shaded areas) indicates formation of heteromeric complexes of hyperactivated forms of cholinesterases. The presence of high-Mw peaks of $A \beta$ and $A p o E$ in these same areas (graphs $\mathbf{A}-\mathbf{F}$; gray shaded areas) supports the notion of formation of BABAC (BuChE/AChE-A $\beta-A p o E$ ) complexes in both $A D$ and control brain extracts. Note that there are combinations of technical and mathematical issues that make the use of error bars in the classical meanings inapplicable in an SDG spectrum. This instead is appreciated by considering both the height and width of the peaks in each SDG spectrum, e.g., a comparison between the heights of individual peaks should be avoided unless their width are reasonably similar.

complexes are formed in the brain. We detected and quantified ApoE protein in the SDG fractions using ELISA. The ApoE SDG diagrams are shown in Figures 1E,F for the control and $\mathrm{AD}$ brain homogenates respectively. These diagrams illustrate the presence of a triple peak at $\mathrm{Mw}$ range of $32-128 \mathrm{kDa}$ (light blue shaded area), containing high levels of ApoE protein. Peaks corresponding to free ApoE (monomers and dimers) molecules are expected to have $\mathrm{Mw}$ of $34-68 \mathrm{kDa}$. Peaks with larger $\mathrm{Mw}$ may hence indicate that some of the ApoE proteins are in complex with other proteins. A comparison between $A \beta$ diagrams (Figures 1A-D) with the ApoE diagrams (Figures 1E,F, light blue shaded area) reveals that $A \beta$ and ApoE proteins co-sedimented as the triple peaks ( $\mathrm{a}^{\prime}, \mathrm{b}^{\prime}$ and $\left.c^{\prime}\right)$ in the $\mathrm{Mw}$ range of $32-128 \mathrm{kDa}$. In other words, the SDG fractions corresponding to these Mw contained both $A \beta$ and $A p o E$, in identical pattern to the $A \beta-A p o E$ complexes previously reported using SDG in vitro on recombinant/purified proteins (Kumar et al., 2016). Thus, we conclude that $A \beta$ ApoE complexes are formed and readily present in the brain. In addition, no apparent differences between the control and $\mathrm{AD}$ brain homogenates were found with regard to the presence of these triple peaks (compare Figures 1A,C,E with Figures 1B,D,F).

Interestingly, we also compared $A \beta_{40}-A p o E$ with $A \beta_{42}-A p o E$ complexes within the control and the AD A $\beta$ SDG diagrams, looking at $A \beta$ peaks in the ApoE-molecular weight areas of the graphs (Figures 1A,B vs. Figures 1C,D, light blue-shaded area). This comparison indicated that a higher proportion of $A \beta_{40}$ peptides were in complex with ApoE than $\mathrm{A} \beta_{42}$ peptides in both $\mathrm{AD}$ and control brains.

\section{BA $\beta A C s$ Are Formed and Present in the Brain}

Our previous report on SDG analysis on both recombinant proteins and CSF samples has also indicated that BuChE and/or $A C h E$ interact with $A \beta$, particularly in the presence of high ApoE protein, and form BuChE/AChE-A $\beta$-ApoE complexes (BA $\beta A C s)$. However, experiments using a selective number of recombinant proteins may not be representative of the more complex biomolecular matrix, naturally present in the brain tissues and parenchymal fluids. We hence determined the SDG pattern of AChE (Figures 1G,H) and BuChE (Figures $\mathbf{1 I}, \mathbf{J}$ ) in the brain homogenates from both $\mathrm{AD}$ and controls, by measuring the activities of $\mathrm{AChE}$ and $\mathrm{BuChE}$ in the SDG fractions.

These two cholinergic enzymes are produced as globular $\left(G_{1}\right)$ subunit, which then assembles from two or four globular subunits to build $G_{2}$ and $G_{4}$ molecular forms of the enzymes. The $G_{1}$ AChE has a molecular weight ranging between $55 \mathrm{kDa}$ and $70 \mathrm{kDa}$, while $\mathrm{G}_{1} \mathrm{BuChE}$ is about $75 \mathrm{kDa}$. Thus, their $G_{2}$ and $G_{4}$ forms are expected to have a $\mathrm{Mw}$ of about $110-150 \mathrm{kDa}$ and $250-280 \mathrm{kDa}$, respectively. In the corresponding SDG diagrams, we indeed observed activity peaks in fractions that exhibited such Mw (Figures 1G-J). However, we also found multiple peaks with molecular weights over $400 \mathrm{kDa}$ to $\sim 1,000 \mathrm{kDa}$. This strongly suggests that these latter peaks were resulting from complex formation between $\mathrm{G}_{2}$ or $\mathrm{G}_{4} \mathrm{AChE} / \mathrm{BuChE}$ and other proteins. A comparison of all the SDG diagrams, specifically within these high-Mw regions (Figure 1, light gray shaded area) shows that ApoE and in particular $A \beta$ also have multiple peaks in this same region, supporting the formation and presence of BA $\beta A C$ in human brain, in similar pattern as it had been observed following similar analyses performed on recombinant/purified human proteins (Kumar et al., 2016).

\section{BAßACs Show High ACh-Hydrolyzing Activities}

One of the main characteristics of BABACs is that the incorporated $\mathrm{BuChE}$ and $\mathrm{AChE}$ enzymes gain a much higher intrinsic ACh-hydrolyzing activity (Kumar et al., 2016). The $\mathrm{AChE}$ and BuChE SDG diagrams presented in Figures 1G-J are based on quantitative enzyme activity assessments. Thus, a comparison between the peak intensities of the activity of the homomeric forms of $\mathrm{AChE}$ or $\operatorname{BuChE}\left(\mathrm{G}_{1}\right.$ to $\left.\mathrm{G}_{4}\right)$ and the intensities of the multiple overlapping high-Mw peaks corresponding to BA $\beta A C s$ clearly indicates that the ACh-hydrolyzing activities of the two enzymes are much higher in BA $\beta A C s$ than in the homomeric molecular forms of these enzymes in the brain. This observation also supports the notion of allosteric modulation of $\mathrm{ChE}$ activities by $\mathrm{A} \beta$ peptides through the formation of BABACs (Kumar et al., 2016).

The BA $\beta A C$ h hypothesis ascribes the allosteric modulation of ACh-hydrolyzing activity of AChE and/or BuChE as one of the native biological function of $A \beta$ peptides in the brain. This hypothesis thereby predicts that $\mathrm{BA} \beta A C$ s should also be present in the brain that is lacking $\mathrm{AD}$ pathology. A comparison between the $\mathrm{AD}$ and control SDG diagrams indicate that $\mathrm{BA} \beta \mathrm{ACs}$ are formed and detectable in both $\mathrm{AD}$ and control brains, supporting the above hypothesis.

\section{Differential Presence of ApoE in BAßACs in $A D$ vs. Control Brain}

Previous observations suggest that high ApoE protein might be one of the driving factors for abnormal stability and accumulation of BAßACs (Darreh-Shori et al., 2006, 2011b; Vijayaraghavan et al., 2014; Kumar et al., 2016). A comparison between the ApoE SDG diagrams of controls vs. ADs in the SDG 
region that corresponds to the $\mathrm{BA} \beta \mathrm{ACs}$ reveals $\mathrm{ApoE}$-containing peaks with higher intensities (peak height) in the $\mathrm{AD}$ brain extracts than control (Figure 1E vs. Figure 1F, gray shaded area; $128-1024 \mathrm{kDa} \mathrm{Mw}$ range).

To further support and complement this finding, we quantified the concentration of $\mathrm{ApoE}$ in the $\mathrm{AD}$ and control brains both in the SDG fractions, specifically in the SDG region that corresponds to the BABACs (Figure 2A), and also in the unfractionated brain homogenates from the same individuals (Figures 2B,C). The results showed that ApoE protein levels were indeed significantly higher in the AD than control brains (all $p$-values $<0.05)$.

\section{BAßACs May be Dysfunctional in the AD Compared to Control Brain}

One of the characteristics of BABACs is that high ApoE protein may alter their disintegration leading to gradual accumulation of enzymatically dormant BA $\beta A C s$, which become readily hyperactivated by excess of $A \beta$ peptide. Considering that $\mathrm{A} \beta$ deposits are one of the key features of $\mathrm{AD}$ brain, the levels of $A \beta$ peptides are expected to be higher in the $\mathrm{AD}$ brain extracts, and consequently $\mathrm{BuChE}$ and/or $\mathrm{AChE}$ activity might be affected. We, therefore, measured the overall BuChE and AChE activities and protein levels in the control and $\mathrm{AD}$ brain homogenates (Figure 3). The results showed that $\mathrm{BuChE}$ activity was significantly higher in the $\mathrm{AD}$ than the control total brain homogenates (average of the three analyzed brain regions; Figure $\mathbf{3 A}$ ) and numerically higher in each distinct brain region (Figure $3 \mathrm{C}$ ). In contrast, the total $\mathrm{BuChE}$ protein levels were essentially identical in the $\mathrm{AD}$ and control brain homogenates (Figure 3B). These findings are consistent with previous reports in AD CSF (DarrehShori et al., 2006, 2011a) and indicate that BuChE exhibits a higher intrinsic catalytic rate per unit of its protein in the $\mathrm{AD}$ brain homogenates most likely due to its interaction with $A \beta$. Thus, high levels of $A p o E$ and $A \beta$ in the $A D$ brain seem to be accompanied by a potentially high degree of abnormal $\mathrm{BA} \beta \mathrm{AC}$ functioning.

In contrast to $\mathrm{A} \beta$ effect on $\mathrm{BuChE}$, prolonged interaction of $\mathrm{A} \beta$ peptides with $\mathrm{AChE}$ is shown to lead to reduction in AChE activity and accumulation of $\mathrm{A} \beta$-inhibited AChE protein (Inestrosa et al., 1996a,b, 2008; Darreh-Shori et al., 2014; Kumar et al., 2016), in particular the read-through AChE-R protein variant (Darreh-Shori et al., 2014). Therefore, we also analyzed both the overall $\mathrm{AChE}$ activity and the proportion of its functional $\mathrm{R}$ and $\mathrm{S}$ splice variant proteins in the $\mathrm{AD}$ and control brain homogenates (Figures 3D-F). While the overall AChE activity and the protein level of AChE-S variant did not differ between the groups (Figures 3D,F), the AChE-R protein was significantly higher in the $\mathrm{AD}$ compared to control brain (Figure 3E). The normalization of the overall AChE activity per unit of AChE-R protein (expressed as $\mathrm{nmol} / \mathrm{min} / \mu \mathrm{g}$ of AChE-R protein) indicated reduced AChE- R activity in the AD brain extracts (Figures 3G,H). Thus, these results confirmed that AChE- $\mathrm{R}$ protein was inactivated in the $\mathrm{AD}$ compared to control brain homogenates.

\section{SDG Spectra Patterns of Homomeric and Heteromeric A $\beta$ Oligomers Are Similar in the Brain and CSF}

As noted, ApoE protein levels may play a role in the normal biofunction and/or biodynamic interaction of the interacting partners in BA $\beta A C s$. In addition, there are indications that ApoE isoproteins may differentially affect the formation of ApoE-A $\beta$ complexes, and thereby the formation of BA $\beta A C s$ (Kumar et al., 2016).

We hence investigated the influence of $A P O E$ genotype and resulting isoproteins on the molecular interactions between $A \beta$, ApoE and ChEs. However, five out of the six available AD brains were from subjects carrying APOE4 (four $\varepsilon 3 / 4$ and one $\varepsilon 4 / 4$ ) genotype. Thereby the brain SDG spectra were sub-analyzed based on three groups of samples: namely AD APOE4+ $(n=5)$; Ctrl APOE4+ $(n=3)$ and Ctrl APOE4- $(n=3)$. In addition, we performed similar APOE4 genotype-based analyses on SDG spectra available from a large group of CSF samples from $\mathrm{AD}$ patients with known APOE genotypes (Figure 4). This way the brain SDG diagrams could be compared along with CSF SDG diagrams.

First, a comparison between the A $\beta$ SDG spectra from the brain homogenates (Figures 1A-D, 4B) and the CSF (Figure 4A) reveals similar peak patterns, regardless of the $\mathrm{AD}$ diagnosis or $A P O E 4$ genotype. For instance, the peaks corresponding to the monomers (denoted by ${ }^{*}$ ) and the homomeric oligomers of $A \beta$ peptides (denoted as the $a$ and $b$ peaks) are evident in the CSF and in the $\mathrm{AD}$ and control brain homogenates SDG spectra for all three APOE4 genotype groups (compare the light green shaded areas in Figure 4A with Figure 4B, and/or Figures 1A-D). However, one interesting exception is that the monomeric $A \beta$ peak $(*$ in Figures 1A-D and $\mathbf{4 A}, \mathbf{B})$ is more evident in the CSF SDG spectra than in the brain (Figure 4A vs. Figures 1A-D and $4 B)$.

Similarly, the broad triple peaks in the $A \beta-A p o E$ complex area in both $A \beta$ and ApoE SDG diagrams are clearly present in both the brain homogenates and CSF (compare the light blue shaded areas in Figures 1A-F, 4B,D with Figures 4A,C). These findings are important and indicate that the formation of homomeric $\mathrm{A} \beta$ oligomers and the heteromeric $\mathrm{A} \beta-\mathrm{ApoE}$ complexes is a physiologically occurring biodynamic phenomenon as they are formed regardless of the $\mathrm{AD}$ diagnosis and the presence or absence of APOE4 risk allele.

\section{Levels of $A \beta$ Oligomers, $A \beta-A p o E$ Complexes and BA $\beta A C$ s Are Lower in APOE4 Carriers in CSF}

The similarity of the brain and CSF SDG spectra patterns opens the possibility to use the CSF SDG spectra (which are based on a much larger number of samples) to investigate the influence of $A P O E$ genotype and resulting isoproteins on the molecular interactions between $A \beta, A p o E$ and ChEs. Indeed, in spite of the pattern similarities among APOE genotypes, the intensities of the homomeric and/or heteromeric $A \beta$ peaks exhibited an $A P O E$-genotype dependance. The twin peaks ( $a$ and $b$ ) corresponding to the homomeric forms of $\mathrm{A} \beta$ 


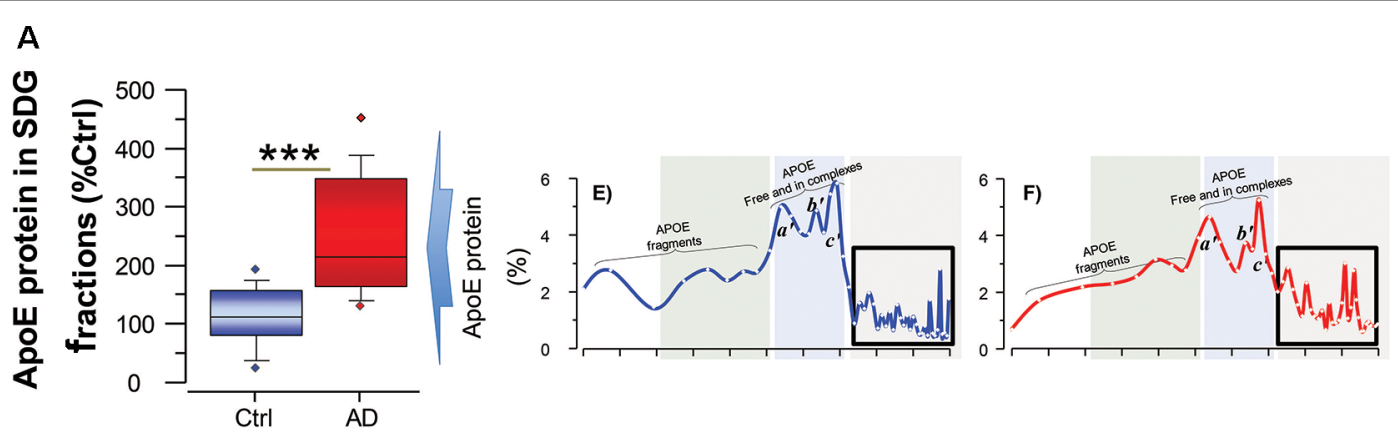

B

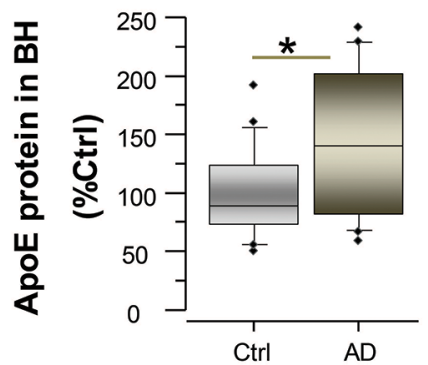

C

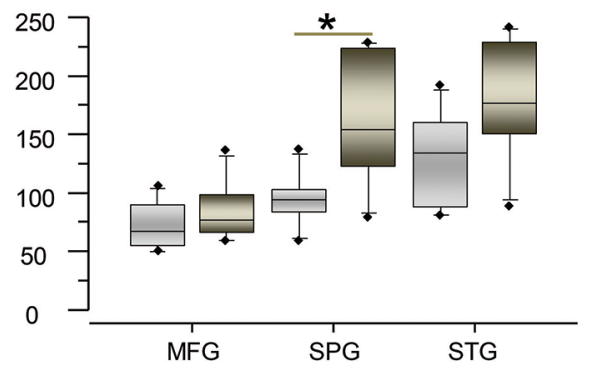

FIGURE 2 | ApoE levels are higher in the brain of AD than controls. ApoE levels were quantified by ELISA both in the SDG fractions (A) and in unfractionated brain homogenates $\mathbf{B}$ ) from the same AD subjects $(n=6)$ and non-demented controls $(n=6)$. Post-mortem brain MFG, STG and SPG regions were used for the measurements. The ApoE levels are presented as percentage of the control brain ApoE. (A) Total ApoE protein levels in the SDG fractions (in the three analyzed brain regions), calculated as sum of the ApoE levels in all fractions with Mw $>200 \mathrm{kDa}$, as indicated by the boxed area in the inset SDG spectra from Figures $\mathbf{1 E}$,F, and shown as average of the three analyzed brain regions. (B,C) Total ApoE protein levels in unfractionated brain homogenates, shown as average of the three analyzed brain regions $\mathbf{( B )}$ and in each region separately $\mathbf{( C )}$. Student's $t$-test ${ }^{* * *} p<0.001,{ }^{*} p<0.05$.

peptides were relatively more intense in CSF of $A P O E^{3 / 3}$ carriers compared to the CSF of carriers of the $\mathrm{AD}$ risk allele $\left(A P O E^{3 / 4}\right.$ and $A P O E^{4 / 4}$; comparison of the green line SDG spectrum with the blue and red ones in Figure 4A). Similarly, the $A P O E^{4 / *}$ carriers (the blue and red line diagrams) showed lower ApoE and ChE peak intensities, compared to non-carriers (green line) in CSF SDG diagrams (Figures 4C,E,G). This is particularly evident in the CSF of the $A P O E^{4 / 4}$ genotype carriers. These observations might be explained by the putative inverse association between CSF $A \beta$ levels and the $A \beta$ deposits in the brain. In other words, lower soluble $A \beta$, ApoE-A $\beta$ complexes and/or BA $\beta A C$ are expected to be present in the CSF of $A P O E^{4 / *}$ carriers than in non-carriers (DarrehShori et al., 2011a; Kumar et al., 2016), as a consequence of high $\mathrm{A} \beta$ deposition in the brain of $A P O E^{4 / *}$ carriers (Darreh-Shori et al., 2011a).

This is also consistent with the finding that ApoE protein is about $130 \%$ higher in the AD SDG fractions (with Mw $>200 \mathrm{kDa}$, Figure $2 \mathrm{~A}$ ) and about $50 \%$ in the $\mathrm{AD}$ brain homogenates (Figures 2B,C) compared to the controls.

\section{DISCUSSION}

In our previous report, we have shown that a diverse range of homomeric and heteromeric forms of $A \beta$ complexes are spontaneously formed (using highly purified proteins) and natively existed in AD CSF samples (Kumar et al., 2016). Here, we used tissue extracts from three different brain regions, namely medial frontal, superior parietal and superior temporal gyri from both $\mathrm{AD}$ and control subjects. In agreement with findings in silico, in vitro, and in AD CSF samples (Kumar et al., 2016), the results indicated that in addition to homomeric (dimeric and tetra-/hexameric) $\mathrm{A} \beta$ oligomers, the brain extracts regardless of the disease status also contained several heteromeric $A \beta$ complexes. The findings also provide evidence that the main source of the heteromeric $\mathrm{A} \beta$ complexes that were detected in CSF is most likely the brain tissues.

This study thereby confirmed and extended our previous findings by showing for the first time evidence that similar homomeric and heteromeric forms of $\mathrm{A} \beta$ complexes natively existed in the brain of patients with $\mathrm{AD}$ and non-demented individuals. The overall pattern of the SDG spectra for the types of homomeric and heteromeric $A \beta$ complexes in the brain was also very similar between patients with $\mathrm{AD}$ and non-demented individuals. Nonetheless, an overall as well as an $A P O E$ genotype-specific comparison revealed, besides a high consistency between the overall SDG spectra patterns in $\mathrm{AD} \mathrm{CSF}$ and the $\mathrm{AD}$ and control brain homogenates, certain qualitative differences in the distribution and levels of homomeric and heteromeric $A \beta$ oligomeric forms among the $\mathrm{AD}$ APOE4+, the Ctrl APOE4+ and the Ctrl APOE4- groups. 

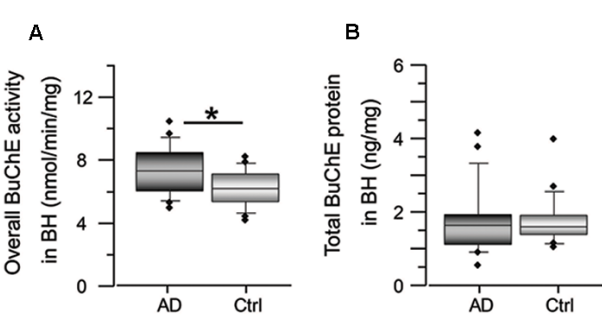

C

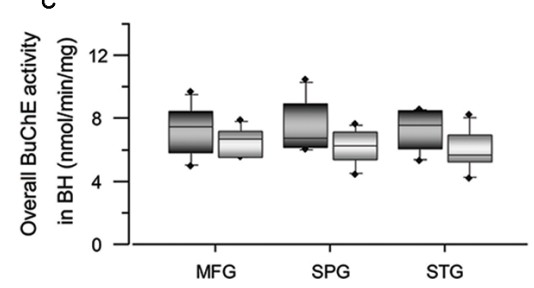

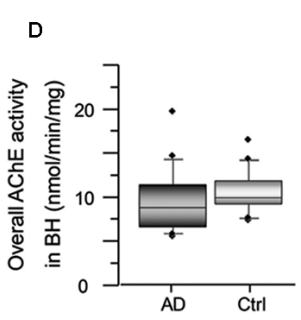

G

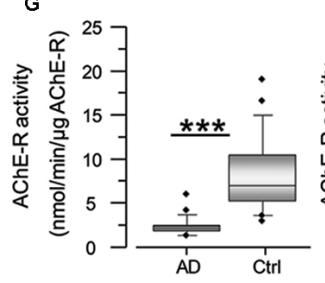

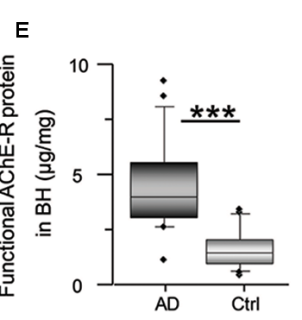

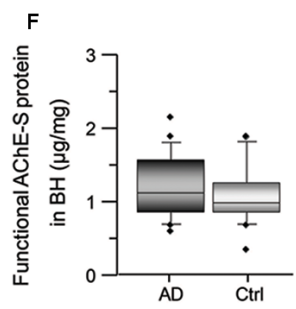

H

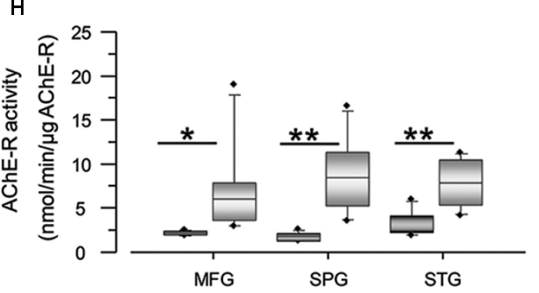

FIGURE 3 | Cholinesterase activity is altered in AD brain, with increase of BuChE activity and decrease of AChE-R activity. Panel (A) shows an increase in the overall BuChE activity in the AD brain compared to the control brain homogenates, normalized to the total protein in the brain extracts. The activity was measured by a modified colorimetric Ellman's assay. Panel (B) shows the corresponding total BuChE protein levels in the brain homogenates quantified by sandwich ELISA. Panel (C) shows the overall BuChE activity in the AD and the control MFG, STG and SPG brain regions separately. Panel (D) shows that the overall AChE activity is similar in the AD brain compared to the control brain homogenates. The activity was measured by a modified colorimetric Ellman's assay. Panels (E,F) show the corresponding protein levels of the functionally intact read-through AChE-R and synaptic AChE-S splice variants of the enzyme in the brain homogenates. These were assayed by a functional semi-sandwich ELISA assay, which utilizes the intrinsic activity of the pre-captured enzymes variants for quantification of their relative amounts in the brain homogenates. It is important to note that these analyses reveal accumulation of inactivated AChE-R variant in the AD brain. This is most simply appreciated from the integrated data of AChE-R activity and protein levels shown in $\mathbf{( G , H ) . ~ T h e ~ r a t i o n a l e ~ i s ~ b u i l t ~ o n ~ t h e ~ m a i n ~ m e t h o d o l o g i c a l ~ d i f f e r e n c e ~ f o r ~ d a t a ~}$ acquisition for graph (D) vs. the graph (E or F). For graph (D), all the components of the brain extract are present in the well when the activity of the enzyme is measured, while the graphs (E,F) are based on activity of the enzymes after capturing the enzyme in the wells, pre-coated with antibody against AChE-R (or AChE-S) variant protein. In other words, in this latter assay all other components present in the brain extracts are washed away. Thus, the higher AChE-R in the AD brain extract in the graph (E) means that something in the brain extract had reversibly inactivated the enzyme, and its removal resulted in the re-activation of the enzyme. AD, Alzheimer's disease $(n=6)$; Ctrl, non-demented controls ( $n=6)$; BuChE, butyrylcholinesterase; AChE, acetylcholinesterase; AChE-R, "Read-through" AChE splice variant protein; AChE-S, "Synaptic" AChE splice variant protein. Student's $t$-test ${ }^{* * *} p<0.001,{ }^{* *} p<0.01,{ }^{*} p<0.05$.

These warrant further investigation since such differences may be crucial for understanding the factors that render the homomeric and/or heteromeric $A \beta$ species pathogenic in individuals at risk of $\mathrm{AD}$.

A longstanding question for us concerns the early and selective degeneration of the central cholinergic system in $\mathrm{AD}$, and its link to $\mathrm{A} \beta$ peptides, to advanced age and to APOE4 genotype. Therefore, the current study similarly to the previous ones focused on analyzing the heteromeric nature of $\mathrm{A} \beta$ peptides in the SDG fractions with regards to ApoE protein and to two known acetylcholine-degrading enzymes, AChE and BuChE. It is hence noteworthy that the current findings do not exclude the possibility for $A \beta$ forming heteromeric complexes with other interacting partners. Indeed, a large number of functional studies on various preparations of $A \beta$ peptides indicate that $A \beta$ also affects other neuronal systems, and cellular pathways signaling machineries such as N-Methyl-D-aspartate (NMDA) receptors, even though such functional outcomes are most often perceived as justification for toxicity of $A \beta$ peptides (for a relevant discussion see Benilova et al., 2012).

Nevertheless, we found that $A \beta$ oligomers natively existed as soluble homomeric forms, i.e., consisting only of $A \beta$ peptides, as well as soluble heteromeric forms, in which $A \beta$ peptides formed highly stable complexes with ApoE protein and/or the cholinergic enzymes AChE and BuChE. This was true for both CSF and the brain extracts regardless of APOE4 genotype and/or $\mathrm{AD}$ disease status. All the detected $\mathrm{A} \beta$ species in the current study "natively" existed/formed since we used as optimized conditions as possible in the preparation of the sucrose gradient solution. One was the omission of detergent in the buffer of sucrose solution to avoid altering the Van der Waals and/or the hydrophobic forces that are crucial in formation of $A \beta$ oligomers as no report exists for the presence of covalent bonding in $A \beta$ oligomers. Similarly, all the detected $\mathrm{A} \beta$ complexes were "highly stable" since they apparently resisted disintegration upon exposure to a continuous ultra-centrifugal force for $16-18 \mathrm{~h}$ at $4^{\circ} \mathrm{C}$. Also, all were "soluble" since none sedimented to the bottom of the SDG tubes.

Altogether, the overall similarity in the diversity, complexity, solubility and stability of the detected monomeric as well as the homomeric and heteromeric forms of $A \beta$ in the AD CSF and the brain extracts of $\mathrm{AD}$ and controls, reinforces the idea that they occur natively in the brain regardless of disease status, and may hence represent native functional units required in a healthy brain. It should be however emphasized that these findings do not suggest that $A \beta$ oligomers or simply $A \beta$ peptides are irrelevant but that just being oligomers does not make them pathological or causes AD. The findings imply that our 

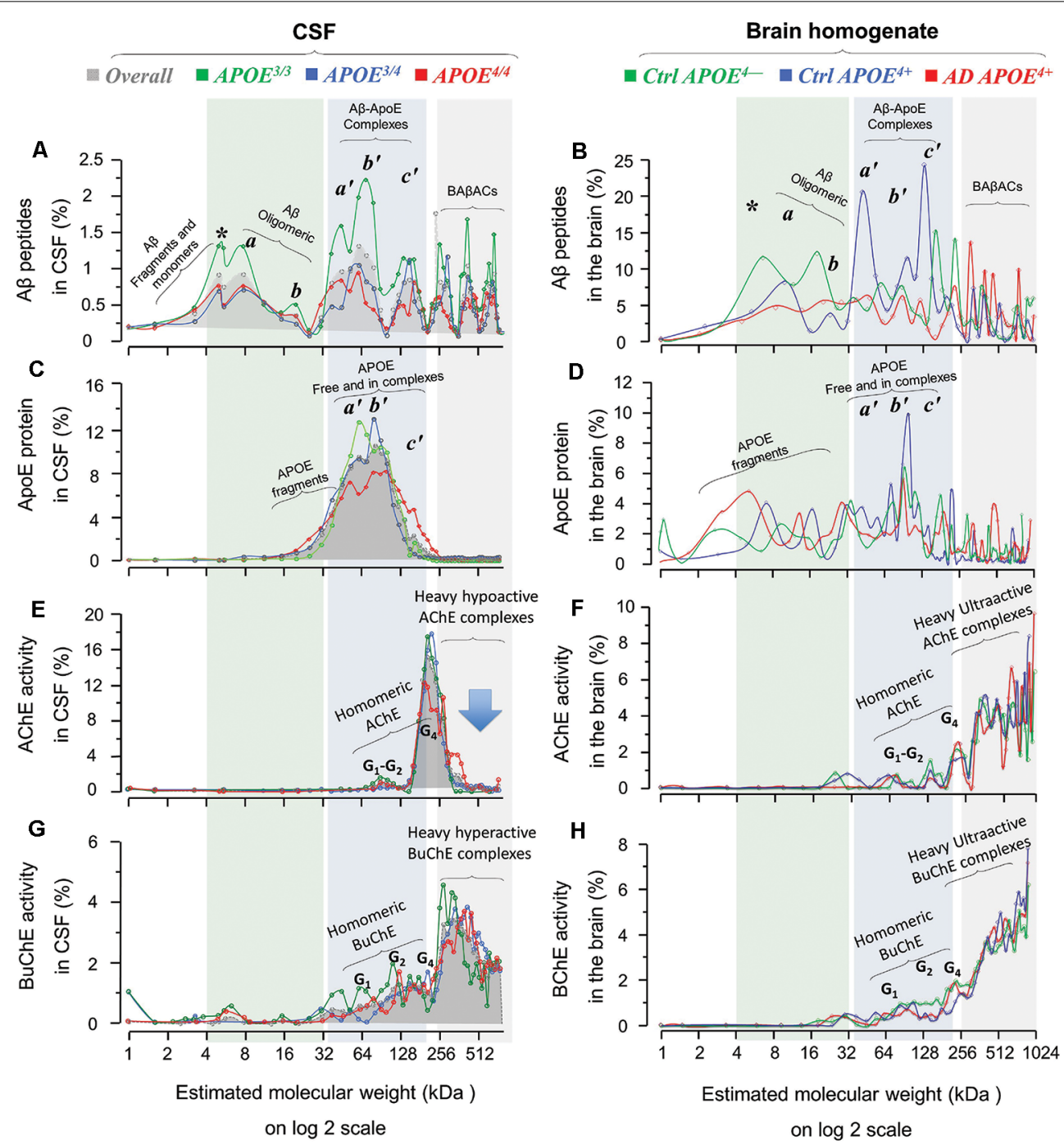

FIGURE 4 | Homomeric and heteromeric forms of A $\beta$, ApoE, cholinesterases and their complexes in post-mortem brain and cerebrospinal fluid (CSF) in relation to $A P O E$ genotype. SDG and ultracentrifugation were used to separate the protein content of nine distinct pooled CSF samples, prepared from 170 AD subjects with known $A P O E$ genotype (3/3, green diagrams; $3 / 4$, blue diagrams; or $4 / 4$, red diagrams; in the spectra panels $\mathbf{A}, \mathbf{C}, \mathbf{E}$ and $\mathbf{G})$. Similar analyses were done on the brain homogenates from a group of $\mathrm{AD}(n=6)$ and non-demented controls $(n=6)$, from three different brain regions, MFG and/or STG and/or SPG. Following o/n ultracentrifugation, the content of each SDG tube was fractionated into $\sim 50$ equal fractions from the bottom of the tubes, and the levels of $A \beta_{1-40}$, $A \beta_{1-42}$, and $A p o E$ proteins, as well as of AChE and BuChE activities were measured in all fractions, as further described in the "Materials and Methods" section. The $y$-axis in all SDG spectra indicates the \% of protein or activity level in each SDG fraction relative to the total level of that protein in the whole SDG gradient. The x-axis shows the log2 transformation of the estimated molecular weight $(\mathrm{Mw})$ for each fraction. The light green shaded area represents low molecular weight fractions, corresponding to $\mathrm{Mw}$ of 4-32 kDa, the light blue shaded area corresponds to $\mathrm{Mw}$ of 32 to $200 \mathrm{kDa}$, and the light gray shaded area corresponds to $\mathrm{Mw}$ ranges between $250 \mathrm{kDa}$ and $1024 \mathrm{kDa}$. The SDG spectra in (A) depict various A $\beta$-containing peaks separated by SDG ultracentrifugation of pooled AD CSF samples, with color-coded indication of the APOE genotype. Panel (B) shows $A \beta$-peaks in the AD and control brain extract samples, with color-coded APOE genotype and disease status indication. Comparison of SDG spectra in the light-green shaded area of $(\mathbf{A}, \mathbf{B})$ reveals essentially similar peak pattern corresponding to $A \beta$ monomers and homomeric $A \beta$ complexes that are detected in both CSF and brain. Peaks marked with * represent A $\beta$ monomers, whereas the peaks a and $b$ correspond to Mw of 8 and $\sim 16 \mathrm{kDa}$, and may hence represent the homomeric dimers and tetramers of $A \beta$, respectively. Panels (C,D) show the corresponding SDG spectra for ApoE-containing peaks in CSF and brain extracts, respectively. The peaks a', b'and c' in the light blue shaded area (Mw range of 32-200 kDa) correspond to both free ApoE protein as well as heteromeric A $\beta$-ApoE complexes. This is readily appreciated from a comparison between $(\mathbf{A}, \mathbf{C})$ and between $(\mathbf{B}, \mathbf{D})$ which confirms the co-sedimentation of $A \beta$ and $A p o E$ in the a', b' and c' $A \beta$-ApoE triple peaks. Nonetheless, these triple peaks in (C) or (D) are broad (or less distinct), indicating that a portion of the peaks most likely represents fragments and free monomeric or dimeric ApoE proteins, with an expected size of $\sim 30,34$ and 68 kD. The peak c' however exhibits a $\mathrm{Mw}>128 \mathrm{kD}$, which is clearly too heavy to consist only of ApoE. The SDG spectra in (E,F) illustrate the peaks of various globular molecular forms $\left(G_{1}, G_{2}\right.$ and $\left.G_{4}\right)$ of $A C h E$ separated based on their relative activity in the SDG fractions of the CSF and brain extracts, respectively. These peaks are accompanied by much heavier AChE-activity peaks (>300 kDa) in both the CSF and the brain SDG spectra. The SDG spectra in $\mathbf{( G , H ) ~ s h o w ~ t h e ~ c o r r e s p o n d i n g ~ f i n d i n g s ~ f o r ~ t h e ~}$ various BuChE molecular forms $\left(G_{1}, G_{2}\right.$ and $\left.G_{4}\right)$ as well as the heavier ( 300-1024 kDa) hyperactive peaks. It should be noted that these heavy AChE and BuChE peaks also exhibit co-sedimentation with the heavy A $\beta$-peaks (as can be seen in $\mathbf{A}, \mathbf{B}$ ), providing evidence for formation of BABACs in the SDG fractions of both 
FIGURE 4 | Continued

the CSF and brain extracts. However, a major difference is detectable in this region for CSF vs. the brain spectra, particularly in case of the heavy

AChE-containing peaks: namely they are relatively hypoactive in CSF (denoted by the arrow in $\mathbf{E}$ ) but are ultra-active in the brain SDG spectra. A more thorough mechanistic explanation for this difference is given in the "Discussion" section, but it should be briefly noted here that this is most likely caused by a prolonged exposure/interaction between $A \beta$ and AChE in CSF which leads to inhibition of AChE (but not BuChE).

efforts need to be focused on deciphering the native physiological functions of these peptides rather than on defining one as the culprit of $\mathrm{AD}$. A crucial approach is hence to identify the effector units of $A \beta$ peptides and elucidate the factors and conditions that can render their biological action pathological.

In this context, ApoE protein may play a crucial role. Our previous report has shown that ApoE protein facilitates the formation of heteromeric $A \beta$ complexes, most likely by chaperoning the physical interaction between $A \beta$ peptides and the ACh-degrading enzymes $\mathrm{BuChE} / \mathrm{AChE}$, resulting in the formation of a functional unit, termed BAßACs (BuChE/AChE- $\beta$-amyloid-APOE complexes; Kumar et al., 2016). The main characteristic of the BA $\beta A C$ s is an $A \beta$-induced allosteric modulation of the activity of the incorporated enzymes, BuChE and AChE (Kumar et al., 2016). Our hypothesis is that BA $\beta A C s$, as dynamic functional units, are continuously formed and disintegrated in the interstitial fluids of the brain. They are required for the regulation of functional status of cholinoceptive astroglial cells, which most often reside far from the cholinergic synapsis. The regulation of their functions requires, therefore, a dynamic adjustment of an extrasynaptic ACh equilibrium state in the brain (Darreh-Shori et al., 2013; Vijayaraghavan et al., 2013; Malmsten et al., 2014). Thereby neuronal release of $A \beta$ promotes the formation of hyperactive $\mathrm{BA} \beta \mathrm{ACs}$, which reduce extrasynaptic ACh levels, resulting in temporal activation of astroglial cells. Reuptake of $\mathrm{A} \beta$ peptides, in contrast, promotes the disintegration of the hyperactive BA $\beta A C s$, allowing the original ACh equilibrium to be reestablished, and thereby forcing astroglial activity back to its original state. Thus, ACh, depending on its concentration, acts either as an activator or a suppressor of activity of non-neuronal cholinoceptive cells via its $\alpha 7$ nicotinic receptors (Darreh-Shori et al., 2013; Vijayaraghavan et al., 2013). Nonetheless, additional reports bring in two other major components of the cholinergic machinery into the picture, namely the high affinity choline transporter, hChT (Cuddy et al., 2017) and the ACh biosynthesizing enzyme, ChAT (Dobransky et al., 2003; Kumar et al., 2018). Cuddy et al. (2017) have found that the $\mathrm{N}$-terminal (amino acids 1-16) of $\mathrm{A} \beta$ peptides binds to and inhibits hChT (Cuddy et al., 2017), which is responsible for cellular reuptake of choline (Cuddy et al., 2017). Dobransky et al. (2003) have reported that A $\beta 42$ peptides somehow alter the phosphorylation state of ChAT protein, which results in several folds increase in the activity of this ACh-biosynthesizing enzyme (Dobransky et al., 2003). Other reports show that $\mathrm{A} \beta$, in particular $\mathrm{A} \beta 42$, peptides are able to allosterically alter the catalytic efficiency of ChAT (NunesTavares et al., 2012; Kumar et al., 2018). Thereby A $\beta$ peptides are able to modulate the activity of ChAT protein both directly and indirectly. Overall, an apparent outcome of the interaction between $A \beta$ and all these cholinergic macromolecules is an alteration in the functional properties of these enzymes and the transporter (Geula et al., 1994; Mesulam and Geula, 1994; Darreh-Shori et al., 2011a,b, 2014; Kumar et al., 2016; Cuddy et al., 2017; Kumar et al., 2018). Intriguingly, A $\beta$ peptides seem to be able to also promote translocation of a certain ChAT variant to the nucleus (Albers et al., 2014), which consequently changes the APP gene expression (Albers et al., 2014; Winick$\mathrm{Ng}$ et al., 2016), indicating that at least the interaction of $\mathrm{A} \beta$ with ChAT has bidirectional consequences. Overall, these observations prompted us to update our hypothesis by proposing that at least one of the innate physiological functions of $A \beta$ peptides is modulation of acetylcholine homeostasis in the brain (Figure 6 in Kumar et al., 2018).

Another characteristic of the BA $\beta A C s$ is that they are highly dynamic complexes with no predetermined size, but approximately range between $400 \mathrm{kDa}$ and $1,000 \mathrm{kDa}$, therefore we have defined them as Light, Heavy and Ultra-heavy BA $\beta A C s$ (Kumar et al., 2016). This characteristic is particularly important for understanding their abnormal function in AD. We have previously hypothesized that abnormally high levels of ApoE protein pathologically alters the normal biodynamics of the interaction between $\mathrm{A} \beta$ and $\mathrm{BChE} / \mathrm{AChE}$ by preventing disintegration of BA $\beta A C s$. The basis for this hypothesis is that we have found that ApoE protein levels are highest $(\sim 150 \%)$ in CSF of patients carrying the $\varepsilon 4$ allele $\left(\varepsilon 4 / 4>>\varepsilon 4 / 3>\varepsilon 3 /{ }^{*}\right)$ (Darreh-Shori et al., 2011b), and that a high ApoE protein level abnormally affects the function, stabilization and accumulation of BAßACs (Darreh-Shori et al., 2011a,b, 2013; Kumar et al., 2016). In a mechanistic view, this means that such an abnormal stabilization of BA $\beta A C$ s results in gradual accumulation of these complexes in the CSF and the interstitial fluids of the brain of patients with AD (Darreh-Shori et al., 2006, 2011a,b, 2014; Kumar et al., 2016). This allows BAßACs to increase in their sizes from the normal Light forms to the Ultra-heavy forms of $\mathrm{BA} \beta \mathrm{ACs}$, which sooner or later will become deposited within the $\mathrm{A} \beta$ deposits in the $\mathrm{AD}$ brain. This, in turn, explains the presence of ApoE, AChE and BuChE in the $\mathrm{A} \beta$ deposits (Mesulam and Geula, 1994; Ramanan et al., 2014), in particular in the brain of AD patients carrying APOE $\varepsilon 4$ allele (Lehmann et al., 1997, 2000). Thus, deposition of ApoE-A $\beta$ complexes and BA $\beta A C$ s within $\mathrm{A} \beta$ plaques in the $\mathrm{AD}$ brain represents the gradual outcome of such molecular interactions as end-point signs of decades of malfunctioning $\mathrm{A} \beta$-effectors complexes such as BA $\beta A C$ s and the related abnormality in acetylcholine homeostasis in the brain.

A comparison between the pattern of SDG diagrams for both ApoE-A $\beta$ and BA $\beta A C$ in the CSF and the brain extracts revealed two main differences that are highly relevant in this context. First, the BA $\beta A C$ s in CSF showed reduced activity (or appeared dormant) as the complexes became heavier, whereas in the brain extracts these complexes showed increased catalytic rate as they grew larger (see Kumar et al., 2016 and compare Figure $4 \mathrm{E}$ or $\mathbf{4 G}$ with Figures $4 \mathrm{~F}$ and $4 \mathbf{H}$ in the current article). This reflects a differential time-dependent effect of $\mathrm{A} \beta$ on the activity of $\mathrm{AChE}$ compared to BuChE 
that are incorporated in the BA $\beta$ ACs (Darreh-Shori et al., 2014). During short-term (up to $4 \mathrm{~h}$ ), interaction of $\mathrm{A} \beta$ peptides with AChE and BChE increases the apparent activity of both enzymes as assessed in CSF samples or in solutions of purified enzyme proteins (Darreh-Shori et al., 2014; Kumar et al., 2016). However upon longer interaction time, AChE but not $\mathrm{BuChE}$ activity is inhibited by $\mathrm{A} \beta$ peptides particularly in presence of high ApoE protein (Darreh-Shori et al., 2014; Kumar et al., 2016). Thus, the initial $A \beta$-induced increase in $\mathrm{BuChE}$ activity remains elevated regardless of the exposure time to $A \beta$ (Darreh-Shori et al., 2014). Given that $A \beta$ and these two enzymes (partly in the form of BA $\beta A C s$ ) coexist in CSF, and that the heaviest BA $\beta A C$ s represent the oldest complexes, it is expected that $\mathrm{AChE}$ activity is inhibited by $\mathrm{A} \beta$ in the oldest complexes, thereby the Ultra-heavy forms of BA $\beta A C s$ display a latent (inactivated) phenotype as is depicted in the AChE SDG spectra (Figure 4E), and to a lesser degree in the BuChE SDG spectra (Figure 4G) in AD CSF. In contrast, the pools of $\mathrm{AChE}, \mathrm{BuChE}$ and $\mathrm{ApoE}$ proteins as well as those of $A \beta$ peptides are most likely separated in intact brain tissues/cells but becomes mixed during the homogenization of the brain tissues, allowing $A \beta$, ApoE and ChEs pools to interact and form BA $\beta A C$. Thus, both enzymes, in particular $\mathrm{AChE}$, are expected to be in hyperactive states in the freshly formed BA $\beta A C s$, as is depicted in the corresponding SDG spectra for the brain extracts (Figures 4F,H; the 256-1024 kDa regions). It should be emphasized here that these specific differences reflect the differences between the nature of CSF and the brain extracts and the disease status because CSF is a naturally occurring extracellular fluid but the used brain extracts are not.

Another informative difference between the SDG pattern of ApoE-A $\beta$ and BA $\beta A C$ s in CSF and in the brain extracts is that much more ApoE protein was found present in the Heavy and Ultra-heavy BAßACs in the brain homogenate compared with the CSF BA $\beta A C s$, which seemed to contain very little (if any) ApoE protein (compare the light gray shaded region in the Figure $4 \mathrm{D}$ with $\mathbf{4 C}$, in the current article). This observation supports the notion that ApoE acts as a chaperon for interaction between $A \beta$ and ChEs, by suggesting that ApoE will be gradually displaced out as the complexes are maturing/growing in their size. On the other hand, a quantitative comparison of ApoE-containing peaks, in regions corresponding to the BA $\beta A C$ s peaks (boxed in the Figure 2A) in the brain SDG spectra between the control and the $\mathrm{AD}$ brain indicated that $\mathrm{BA} \beta \mathrm{ACs}$ contained more ApoE protein in the $\mathrm{AD}$ brain homogenate than in the controls. We also found that the amount of ApoE protein was higher in the total $\mathrm{AD}$ brain extracts compared to the control samples, in agreement with CSF findings (Darreh-Shori et al., 2011a,b). These observations are important since they indicate a high ApoE protein resulted in excessive ApoE chaperoning effect on the formation of $\mathrm{BA} \beta \mathrm{ACs}$ in the $\mathrm{AD}$ brain homogenates. In support of this notion, we found a higher amount of hyperactivated AChE- R protein in the $\mathrm{AD}$ brain extracts compared to the control brain extracts, thereby indicating a higher degree of $\mathrm{BA} \beta \mathrm{ACs}$ formation in the $\mathrm{AD}$ brain extracts. As might be expected the activity but not the protein level of BuChE was also significantly higher in the $\mathrm{AD}$ than the control brain homogenates, indicating a larger number of hyperactivated $\mathrm{BuChE}$ were formed in the $\mathrm{AD}$ cases when the tissues were homogenized. Overall, while BA $\beta A C$ s as effector units of $A \beta$ represent one possible innate functions of $A \beta$ peptides required for modulation of ACh homeostasis in the brain, a high ApoE protein (mainly as a function of the AD risk allele of $A P O E$ ) represents a possible condition that may render this innate $\mathrm{A} \beta$ activity pathogenic.

Noteworthy, high ApoE protein in CSF of AD patients has been found to be associated with dementia and in vivo pathological signs of AD (Darreh-Shori et al., 2011a; Vijayaraghavan et al., 2014). These observations have further been confirmed by a study in a large well-characterized population of patients with subjective cognitive decline (SCD) or mild cognitive impairment (MCI). The study further suggests that high CSF ApoE predicts the clinical progression in APOE $\varepsilon 4$-carriers (van Harten et al., 2017). Thus, our findings provide a mechanistic explanation by suggesting that abnormally high levels of ApoE protein in the brain may mediate, through excessive formation of ApoE-A $\beta$ chaperone units, an abnormal formation, accumulation and stabilization of BA $\beta A C$ in the interstitial fluids in the brain. This is expected to cause a gradual and detrimental alteration of the delicate dynamic association and dissociation of $\mathrm{A} \beta$ with ChEs in forming a functional unit for maintaining a proper ACh signaling, most likely for both cholinergic neurotransmission and extrasynaptic action of Ach (Darreh-Shori et al., 2011a,b; Vijayaraghavan et al., 2014; van Harten et al., 2017). Furthermore, observational studies on the use of cholesterol-lowering drugs indicate that they may be protective against development of $\mathrm{AD}$ and/or $\mathrm{A} \beta$ pathology (Shepardson et al., 2011). Given that reducing cholesterol and lipid synthesis may also decrease the physiological demand on ApoE protein expression, and thereby at least indirectly reduce the levels of ApoE, our findings suggest that the protective effect of these drugs against $\mathrm{AD}$ development may be mediated through a reduced $\mathrm{A} \beta-\mathrm{ApoE}$ and $\mathrm{BA} \beta \mathrm{ACs}$ accumulation. Indeed, there is evidence of increased AChE activity in patients with familial hypercholesterolemia and in animal models of hypercholesterolemia (Moreira et al., 2014; Lopes et al., 2015). Altogether, the previous and current findings provide solid scientific premises suggesting that development of effective ApoE lowering drugs is a highly viable preventive strategy against the development of $\mathrm{AD}$. However, it is difficult to predict whether such drugs would be able to show measurable efficacy if they are tested in patients already suffering from AD. The best study populations are patients with SCD or very mild MCI if such drugs have to be tested in patients with clinical symptomatology.

$\mathrm{A} \beta$ oligomers are considered the toxic species and the culprit actors in $\mathrm{AD}$ (Klein, 2002). However, the definition of $\mathrm{A} \beta$ oligomers, their molecular nature, their concentrations and the techniques that most often are employed to access these characteristics need to be critically revised. In the current work and a previous study we showed that the SDG fractionation technique is highly feasible, suitable and superior to achieve the 
aforementioned information, in particular since the separation occurs without major manipulation of the native conditions of the proteins in the samples. Several studies have reported that the amount of $\mathrm{A} \beta$ oligomers in the brain extracts and/or CSF are either in very low $(<1 \mathrm{pM}$ and $<6.3 \mathrm{pg} / \mathrm{mL})$ ranges or simply under detection level of the conventional quantitative assays (Georganopoulou et al., 2005; Esparza et al., 2013; Yang et al., 2013). In strong contrast, we showed here that an in-house ELISA assay, with regular sensitivity, readily detected a large number of various $A \beta$ species (with apparent $M w$ corresponding to monomeric, dimeric and tetrameric species, up to as large as $1,000 \mathrm{kD}$ complexes). The majority of studies on $\mathrm{A} \beta$ oligomers have used either immunoprecipitation (IP) or Western-blot (WB) techniques on brain homogenates, CSF or cell extracts. These techniques require either pre-clearance and/or mixing the samples with a buffer, which often contains high concentration of a reducing agent and/or high concentration of various detergents, such as Triton X-100 or sodium dodecyl sulfate (SDS), followed by heat denaturation of proteins in the samples (Lesné et al., 2013). The use of such detergents, in particular SDS is highly problematic and may cause artificial aggregation (Barghorn et al., 2005) or disaggregation of the native $A \beta$ complexes that the current study and our previous reports have shown to exist/form in vitro and ex vivo in CSF and brain extracts (Darreh-Shori et al., 2014; Kumar et al., 2016). Furthermore, the presence of various forms of $A \beta$ oligomers that most often inferred to be the homomeric variants is depicted as more or less distinct bands on the WB membrane, immunostained with anti-A $\beta$ antibodies. The migration pattern of the $\mathrm{A} \beta$ bands corresponds to $\mathrm{Mw}$ ranging from $8 \mathrm{kDa}$ to $\sim 200 \mathrm{kD}$. To the best of our knowledge very few (if any) have used double staining of the bands to ascertain that they were really representing only homomeric forms of $\mathrm{A} \beta$ complexes. One study by this laboratory, however, used double staining with an anti-A $\beta$ antibody on a set of WB membranes that had been previously used for detection of AChE protein in SDG fractions of CSF samples (Darreh-Shori et al., 2014). The study showed that the anti-A $\beta$ antibody positively stained a heavy band that had been also immunodetected with an anti-AChE antibody. This not only supports our findings but also strongly highlights the lack of consideration about the possibility for the heteromeric nature of $A \beta$ oligomers in the field.

The light homomeric forms of $\mathrm{A} \beta$ oligomers have been claimed difficult to detect and isolate in brain extracts, and particularly in CSF (Georganopoulou et al., 2005; Esparza et al., 2013; Yang et al., 2013). This study and another recent one by this laboratory showed that these $A \beta$ oligomers were readily detected following SDG fractionation, regardless of whether the analyzed samples were a mixture of purified proteins $(\mathrm{A} \beta$ with ApoE and/or ChEs), human CSF, or brain tissue extracts (Kumar et al., 2016). Another group has successfully used a reasonably similar ultracentrifugation technique on brain extracts (Esparza et al., 2016). Although they also detected $\mathrm{A} \beta$ complexes with $\mathrm{Mw}$ of about $670 \mathrm{kDa}$ (in the range of $\mathrm{BA} \beta \mathrm{ACs}$ ), their focus has been limited to the detection and isolation of the light homomeric $\mathrm{A} \beta$ oligomers of a defined size, and they did not analyze the heteromeric complexes, nor used control brain homogenates for comparison but for testing the stability of the isolated $A \beta$ oligomers (Esparza et al., 2016).

\section{CONCLUSION}

In summary, the current study provided novel evidence that distinct $A \beta_{40}$ and $A \beta_{42}$ oligomers did natively exist in the brain of both $\mathrm{AD}$ and non-demented individuals. This was true for both homomeric and heteromeric forms of $A \beta_{40}$ and $A \beta_{42}$, indicating that they have a physiological role in the healthy brain, in addition to be abnormally involved in pathological processes. This study also provided evidence that the origin of $\mathrm{A} \beta-\mathrm{ApoE}$ and $\mathrm{BA} \beta \mathrm{AC}$ complexes in CSF is most likely from the interstitial fluids in the brain. The readily detectable presence of such a large number of $\mathrm{A} \beta$ species implies that the homomeric and heteromeric formation of $\mathrm{A} \beta$ oligomers is an innate dynamic process, which is largely independent of the disease status as they formed in the brain extracts of $\mathrm{AD}$ patients and non-demented individuals.

\section{DATA AVAILABILITY}

The datasets for this manuscript are not publicly available because the raw data generated and analyzed during this study are available from the corresponding author upon reasonable request. Requests to access the datasets should be directed to taher.darreh-shori@ki.se.

\section{ETHICS STATEMENT}

This study was conducted according to the Declaration of Helsinki and subsequent revisions. All studies involving human subjects were approved by the Regional Ethical Review Board in Stockholm or the Research Ethics Committee of the South Huddinge University Hospital. The brain tissues were obtained from Netherlands Brain Bank (NBB), Netherlands Institute for Neuroscience, Amsterdam. The NBB abides by the Dutch law for obtaining and using human tissues for scientific research. All material had been collected from donors from whom a written informed consent for brain autopsy and the use of the material and clinical information for research purposes had been obtained by the NBB.

\section{AUTHOR CONTRIBUTIONS}

The concept and design of the study was done by TD-S. EL, AG and SJ performed the experiments. EL and TD-S analyzed the data. EL, TD-S and CUL wrote the manuscript. AN provided critical input during the study and during the preparation of the manuscript. All authors read and approved the final manuscript.

\section{FUNDING}

This study was supported by grants from Loo and Hans Osterman Foundation; KI Foundations; KI Geriatrics Foundations; Olle Engkvist Byggmästare Foundation; Åke 
Wibergs Foundation; Åhlén Foundation; Gunvor and Josef Anér Foundation; Magnus Bergvall Foundation; The Lars Hierta Memorial Foundation; Demensfonden; Gun and Bertil Stohne Foundation; Foundation for Sigurd \& Elsa Golje Memory; Tore Nilsson Foundation; the Foundation for Old Servants; the Swedish Brain Foundation; the Stockholm County Council (ALF project); Alzheimer Association, USA (2016-

\section{REFERENCES}

Albers, S., Inthathirath, F., Gill, S. K., Winick-Ng, W., Jaworski, E., Wong, D. Y., et al. (2014). Nuclear $82-\mathrm{kDa}$ choline acetyltransferase decreases amyloidogenic APP metabolism in neurons from APP/PS1 transgenic mice. Neurobiol. Dis. 69, 32-42. doi: 10.1016/j.nbd.2014.05.008

Barghorn, S., Nimmrich, V., Striebinger, A., Krantz, C., Keller, P., Janson, B., et al. (2005). Globular amyloid beta-peptide oligomer - a homogenous and stable neuropathological protein in Alzheimer's disease. J. Neurochem. 95, 834-847. doi: 10.1111/j.1471-4159.2005.03407.x

Benilova, I., Karran, E., and De Strooper, B. (2012). The toxic A $\beta$ oligomer and Alzheimer's disease: an emperor in need of clothes. Nat. Neurosci. 15, 349-357. doi: $10.1038 / \mathrm{nn} .3028$

Cirrito, J. R., Yamada, K. A., Finn, M. B., Sloviter, R. S., Bales, K. R., May, P. C., et al. (2005). Synaptic activity regulates interstitial fluid amyloid- $\beta$ levels in vivo. Neuron 48, 913-922. doi: 10.1016/j.neuron.2005.10.028

Cohen, M. L., Kim, C., Haldiman, T., ElHag, M., Mehndiratta, P., Pichet, T., et al. (2015). Rapidly progressive Alzheimer's disease features distinct structures of amyloid- $\beta$. Brain 138, 1009-1022. doi: 10.1093/brain/awv006

Connor, J. R., Tucker, P., Johnson, M., and Snyder, B. (1993). Ceruloplasmin levels in the human superior temporal gyrus in aging and Alzheimer's disease. Neurosci. Lett. 159, 88-90. doi: 10.1016/0304-3940(93) 90805-u

Cuddy, L. K., Seah, C., Pasternak, S. H., and Rylett, R. J. (2017). Amino-terminal $\beta$-amyloid antibody blocks $\beta$-amyloid-mediated inhibition of the high-affinity choline transporter CHT. Front. Mol. Neurosci. 10:361. doi: 10.3389/fnmol. 2017.00361

Darreh-Shori, T., Brimijoin, S., Kadir, A., Almkvist, O., and Nordberg, A. (2006). Differential CSF butyrylcholinesterase levels in Alzheimer's disease patients with the ApoE epsilon4 allele, in relation to cognitive function and cerebral glucose metabolism. Neurobiol. Dis. 24, 326-333. doi: 10.1016/j.nbd.2006. 07.013

Darreh-Shori, T., Forsberg, A., Modiri, N., Andreasen, N., Blennow, K., Kamil, C., et al. (2011a). Differential levels of apolipoprotein E and butyrylcholinesterase show strong association with pathological signs of Alzheimer's disease in the brain in vivo. Neurobiol. Aging 32, 2320.e15-2320.e32. doi: 10.1016/j. neurobiolaging.2010.04.028

Darreh-Shori, T., Modiri, N., Blennow, K., Baza, S., Kamil, C., Ahmed, H., et al. (2011b). The apolipoprotein E $\varepsilon 4$ allele plays pathological roles in AD through high protein expression and interaction with butyrylcholinesterase. Neurobiol. Aging 32, 1236-1248. doi: 10.1016/j.neurobiolaging.2009.07.015

Darreh-Shori, T., Hosseini, S. M., and Nordberg, A. (2014). Pharmacodynamics of cholinesterase inhibitors suggests add-on therapy with a low-dose carbamylating inhibitor in patients on long-term treatment with rapidly reversible inhibitors. J. Alzheimers Dis. 39, 423-440. doi: 10.3233/jad130845

Darreh-Shori, T., Vijayaraghavan, S., Aeinehband, S., Piehl, F., Lindblom, R. P., Nilsson, B., et al. (2013). Functional variability in butyrylcholinesterase activity regulates intrathecal cytokine and astroglial biomarker profiles in patients with Alzheimer's disease. Neurobiol. Aging 34, 2465-2481. doi: 10.1016/j. neurobiolaging.2013.04.027

Diamant, S., Podoly, E., Friedler, A., Ligumsky, H., Livnah, O., and Soreq, H. (2006). Butyrylcholinesterase attenuates amyloid fibril formation in vitro. Proc. Natl. Acad. Sci. U S A 103, 8628-8633. doi: 10.1073/pnas.0602922103

Dobransky, T., Brewer, D., Lajoie, G., and Rylett, R. J. (2003). Phosphorylation of $69-\mathrm{kDa}$ choline acetyltransferase at threonine 456 in response to amyloid- $\beta$ peptide 1-42. J. Biol. Chem. 278, 5883-5893. doi: 10.1074/jbc.m212080200
NIRG-391599); and the Swedish Research Council (project no 2016-01806).

\section{ACKNOWLEDGMENTS}

We thank the Netherlands Brain Bank for providing the post-mortem brain tissues.

Esparza, T. J., Wildburger, N. C., Jiang, H., Gangolli, M., Cairns, N. J., Bateman, R. J., et al. (2016). Soluble amyloid- $\beta$ aggregates from human Alzheimer's disease brains. Sci. Rep. 6:38187. doi: 10.1038/srep38187

Esparza, T. J., Zhao, H., Cirrito, J. R., Cairns, N. J., Bateman, R. J., Holtzman, D. M., et al. (2013). Amyloid- $\beta$ oligomerization in Alzheimer dementia versus high-pathology controls. Ann. Neurol. 73, 104-119. doi: 10.1002/ana.23748

Fogel, H., Frere, S., Segev, O., Bharill, S., Shapira, I., Gazit, N., et al. (2014). APP homodimers transduce an amyloid- $\beta$-mediated increase in release probability at excitatory synapses. Cell Rep. 7, 1560-1576. doi: 10.1016/j.celrep.2014.04.024

Georganopoulou, D. G., Chang, L., Nam, J. M., Thaxton, C. S., Mufson, E. J., Klein, W. L., et al. (2005). Nanoparticle-based detection in cerebral spinal fluid of a soluble pathogenic biomarker for Alzheimer's disease. Proc. Natl. Acad. Sci. U S A 102, 2273-2276. doi: 10.1073/pnas.0409336102

Geula, C., Greenberg, B. D., and Mesulam, M. M. (1994). Cholinesterase activity in the plaques, tangles and angiopathy of Alzheimer's disease does not emanate from amyloid. Brain Res. 644, 327-330. doi: 10.1016/0006-8993(94) 91697-7

Ghiso, J., Matsubara, E., Koudinov, A., Choi-Miura, N. H., Tomita, M., Wisniewski, T., et al. (1993). The cerebrospinal-fluid soluble form of Alzheimer's amyloid $\beta$ is complexed to SP-40,40 (apolipoprotein J), an inhibitor of the complement membrane-attack complex. Biochem. J. 293, 27-30. doi: 10.1042/bj2930027

Gong, Y., Chang, L., Viola, K. L., Lacor, P. N., Lambert, M. P., Finch, C. E., et al. (2003). Alzheimer's disease-affected brain: presence of oligomeric $\mathrm{A} \beta$ ligands (ADDLs) suggests a molecular basis for reversible memory loss. Proc. Natl. Acad. Sci. U S A 100, 10417-10422. doi: 10.1073/pnas. 1834302100

Inestrosa, N. C., Alvarez, A., and Calderón, F. (1996a). Acetylcholinesterase is a senile plaque component that promotes assembly of amyloid $\beta$-peptide into Alzheimer's filaments. Mol. Psychiatry 1, 359-361.

Inestrosa, N. C., Alvarez, A., Perez, C. A., Moreno, R. D., Vicente, M., Linker, C., et al. (1996b). Acetylcholinesterase accelerates assembly of amyloid- $\beta$-peptides into Alzheimer's fibrils: possible role of the peripheral site of the enzyme. Neuron 16, 881-891. doi: 10.1016/s0896-6273(00)80108-7

Inestrosa, N. C., Dinamarca, M. C., and Alvarez, A. (2008). Amyloidcholinesterase interactions: implications for Alzheimer's disease. FEBS J. 275, 625-632. doi: 10.1111/j.1742-4658.2007.06238.x

Kang, J. E., Lim, M. M., Bateman, R. J., Lee, J. J., Smyth, L. P., Cirrito, J. R., et al. (2009). Amyloid- $\beta$ dynamics are regulated by orexin and the sleep-wake cycle. Science 326, 1005-1007. doi: 10.1126/science.1180962

Kay, A., Petzold, A., Kerr, M., Keir, G., Thompson, E., and Nicoll, J. (2003). Temporal alterations in cerebrospinal fluid amyloid $\beta$-protein and apolipoprotein E after subarachnoid hemorrhage. Stroke 34, e240-e243. doi: 10.1161/01.STR.0000100157.88508.2F

Klein, W. L. (2002). A $\beta$ toxicity in Alzheimer's disease: globular oligomers (ADDLs) as new vaccine and drug targets. Neurochem. Int. 41, 345-352. doi: 10.1016/s0197-0186(02)00050-5

Klein, W. L., Krafft, G. A., and Finch, C. E. (2001). Targeting small A $\beta$ oligomers: the solution to an Alzheimer's disease conundrum? Trends Neurosci. 24 219-224. doi: 10.1016/s0166-2236(00)01749-5

Kumar, A., Lana, E., Kumar, R., Lithner, C. U., and Darreh-Shori, T. (2018). Soluble A $\beta 42$ acts as allosteric activator of the core cholinergic enzyme choline acetyltransferase. Front. Mol. Neurosci. 11:327. doi: 10.3389/fnmol.2018. 00327

Kumar, R., Nordberg, A., and Darreh-Shori, T. (2016). Amyloid- $\beta$ peptides act as allosteric modulators of cholinergic signalling through formation of soluble BAßACs. Brain 139, 174-192. doi: 10.1093/brain/awv318 
Lambert, M. P., Viola, K. L., Chromy, B. A., Chang, L., Morgan, T. E., Yu, J., et al. (2001). Vaccination with soluble $A \beta$ oligomers generates toxicity-neutralizing antibodies. J. Neurochem. 79, 595-605. doi: 10.1046/j.1471-4159.2001. 00592.x

Lehmann, D. J., Johnston, C., and Smith, A. D. (1997). Synergy between the genes for butyrylcholinesterase $\mathrm{K}$ variant and apolipoprotein $\mathrm{E} 4$ in late-onset confirmed Alzheimer's disease. Hum. Mol. Genet. 6, 1933-1936. doi: $10.1093 / \mathrm{hmg} / 6.11 .1933$

Lehmann, D. J., Nagy, Z., Litchfield, S., Borja, M. C., and Smith, A. D. (2000). Association of butyrylcholinesterase $\mathrm{K}$ variant with cholinesterase-positive neuritic plaques in the temporal cortex in late-onset Alzheimer's disease. Hum. Genet. 106, 447-452. doi: 10.1007/s004390000277

Lesné, S. E., Sherman, M. A., Grant, M., Kuskowski, M., Schneider, J. A., Bennett, D. A., et al. (2013). Brain amyloid- $\beta$ oligomers in ageing and Alzheimer's disease. Brain 136, 1383-1398. doi: 10.1093/brain/awt062

Lopes, J. B., de Oliveira, J., Engel, D. F., de Paula, G. C., Moreira, E. L., and de Bem, A. F. (2015). Efficacy of donepezil for cognitive impairments in familial hypercholesterolemia: preclinical proof of concept. CNS Neurosci. Ther. 21, 964-966. doi: 10.1111/cns.12479

Malmsten, L., Vijayaraghavan, S., Hovatta, O., Marutle, A., and DarrehShori, T. (2014). Fibrillar $\beta$-amyloid 1-42 alters cytokine secretion, cholinergic signalling and neuronal differentiation. J. Cell. Mol. Med. 18, 1874-1888. doi: $10.1111 /$ jcmm. 12343

Mesulam, M. M., and Geula, C. (1994). Butyrylcholinesterase reactivity differentiates the amyloid plaques of aging from those of dementia. Ann. Neurol. 36, 722-727. doi: 10.1002/ana.410360506

Moreira, E. L., de Oliveira, J., Engel, D. F., Walz, R., de Bem, A. F., Farina, M., et al. (2014). Hypercholesterolemia induces short-term spatial memory impairments in mice: up-regulation of acetylcholinesterase activity as an early and causal event? J. Neural Transm. 121, 415-426. doi: 10.1007/s00702-0131107-9

Neufang, S., Akhrif, A., Riedl, V., Forstl, H., Kurz, A., Zimmer, C., et al. (2011). Disconnection of frontal and parietal areas contributes to impaired attention in very early Alzheimer's disease. J. Alzheimers Dis. 25, 309-321. doi: 10.3233/jad2011-102154

Nicoll, J. A., Wilkinson, D., Holmes, C., Steart, P., Markham, H., and Weller, R. O. (2003). Neuropathology of human Alzheimer disease after immunization with amyloid- $\beta$ peptide: a case report. Nat. Med. 9, 448-452. doi: 10.1038/nm840

Nunes-Tavares, N., Santos, L. E., Stutz, B., Brito-Moreira, J., Klein, W. L., Ferreira, S. T., et al. (2012). Inhibition of choline acetyltransferase as a mechanism for cholinergic dysfunction induced by amyloid- $\beta$ peptide oligomers. J. Biol. Chem. 287, 19377-19385. doi: 10.1074/jbc.m111. 321448

O'Brien, R. J., and Wong, P. C. (2011). Amyloid precursor protein processing and Alzheimer's disease. Annu. Rev. Neurosci. 34, 185-204. doi: 10.1146/annurevneuro-061010-113613

Podoly, E., Bruck, T., Diamant, S., Melamed-Book, N., Weiss, A., Huang, Y., et al. (2008). Human recombinant butyrylcholinesterase purified from the milk of transgenic goats interacts with $\beta$-amyloid fibrils and suppresses their formation in vitro. Neurodegener. Dis. 5, 232-236. doi: 10.1159/ 000113711

Ramanan, V. K., Risacher, S. L., Nho, K., Kim, S., Swaminathan, S., Shen, L., et al. (2014). APOE and BCHE as modulators of cerebral amyloid deposition: a florbetapir PET genome-wide association study. Mol. Psychiatry 19, 351-357. doi: $10.1038 / \mathrm{mp} .2013 .19$

Rees, T., Hammond, P. I., Soreq, H., Younkin, S., and Brimijoin, S. (2003). Acetylcholinesterase promotes $\beta$-amyloid plaques in cerebral cortex. Neurobiol. Aging 24, 777-787. doi: 10.1016/s0197-4580(02)00230-0

Saunders, A. M., Strittmatter, W. J., Schmechel, D., George-Hyslop, P. H., PericakVance, M. A., Joo, S. H., et al. (1993). Association of apolipoprotein E allele epsilon 4 with late-onset familial and sporadic Alzheimer's disease. Neurology 43, 1467-1472. doi: 10.1212/wnl.43.8.1467
Schmechel, D. E., Saunders, A. M., Strittmatter, W. J., Crain, B. J., Hulette, C. M., Joo, S. H., et al. (1993). Increased amyloid $\beta$-peptide deposition in cerebral cortex as a consequence of apolipoprotein E genotype in late-onset Alzheimer disease. Proc. Natl. Acad. Sci. U S A 90, 9649-9653. doi: 10.1073/pnas.90.20. 9649

Shepardson, N. E., Shankar, G. M., and Selkoe, D. J. (2011). Cholesterol level and statin use in Alzheimer disease: II. Review of human trials and recommendations. Arch. Neurol. 68, 1385-1392. doi: 10.1001/archneurol. 2011.242

Strittmatter, W. J., Saunders, A. M., Schmechel, D., Pericak-Vance, M., Enghild, J., Salvesen, G. S., et al. (1993a). Apolipoprotein E: high-avidity binding to $\beta$-amyloid and increased frequency of type 4 allele in late-onset familial Alzheimer disease. Proc. Natl. Acad. Sci. U S A 90, 1977-1981. doi: $10.1073 /$ pnas.90.5.1977

Strittmatter, W. J., Weisgraber, K. H., Huang, D. Y., Dong, L. M., Salvesen, G. S., Pericak-Vance, M., et al. (1993b). Binding of human apolipoprotein E to synthetic amyloid $\beta$ peptide: isoform-specific effects and implications for late-onset Alzheimer disease. Proc. Natl. Acad. Sci. U S A 90, 8098-8102. doi: 10.1073/pnas.90.17.8098

van Harten, A. C., Jongbloed, W., Teunissen, C. E., Scheltens, P., Veerhuis, R., and van der Flier, W. M. (2017). CSF ApoE predicts clinical progression in nondemented APOE\&4 carriers. Neurobiol. Aging 57, 186-194. doi: 10.1016/j. neurobiolaging.2017.04.002

Vijayaraghavan, S., Karami, A., Aeinehband, S., Behbahani, H., Grandien, A., Nilsson, B., et al. (2013). Regulated extracellular choline acetyltransferase activity- the plausible missing link of the distant action of acetylcholine in the cholinergic anti-inflammatory pathway. PLoS One 8:e65936. doi: 10.1371/journal.pone.0065936

Vijayaraghavan, S., Maetzler, W., Reimold, M., Lithner, C. U., Liepelt-Scarfone, I., Berg, D., et al. (2014). High apolipoprotein $\mathrm{E}$ in cerebrospinal fluid of patients with Lewy body disorders is associated with dementia. Alzheimers Dement. 10, 530.e1-540.e1. doi: 10.1016/j.jalz.2013.03.010

Walsh, D. M., and Selkoe, D. J. (2004). Oligomers on the brain: the emerging role of soluble protein aggregates in neurodegeneration. Protein Pept. Lett. 11, 213-228. doi: 10.2174/0929866043407174

Willem, M., Tahirovic, S., Busche, M. A., Ovsepian, S. V., Chafai, M., Kootar, S., et al. (2015). $\eta$-Secretase processing of APP inhibits neuronal activity in the hippocampus. Nature 526, 443-447. doi: 10.1038/nature14864

Winick-Ng, W., Caetano, F. A., Winick-Ng, J., Morey, T. M., Heit, B., and Rylett, R. J. (2016). 82-kDa choline acetyltransferase and SATB1 localize to $\beta$-amyloid induced matrix attachment regions. Sci. Rep. 6:23914. doi: $10.1038 /$ srep23914

Wisniewski, T., Golabek, A., Matsubara, E., Ghiso, J., and Frangione, B. (1993). Apolipoprotein E: binding to soluble Alzheimer's $\beta$-amyloid. Biochem. Biophys. Res. Commun. 192, 359-365. doi: 10.1006/bbrc.1993.1423

Yang, T., Hong, S., O'Malley, T., Sperling, R. A., Walsh, D. M., and Selkoe, D. J. (2013). New ELISAs with high specificity for soluble oligomers of amyloid $\beta$-protein detect natural $A \beta$ oligomers in human brain but not CSF. Alzheimers Dement. 9, 99-112. doi: 10.1016/j.jalz.2012. 11.005

Conflict of Interest Statement: The authors declare that the research was conducted in the absence of any commercial or financial relationships that could be construed as a potential conflict of interest.

Copyright (c) 2019 Lana, Gellerbring, Jung, Nordberg, Unger Lithner and DarrehShori. This is an open-access article distributed under the terms of the Creative Commons Attribution License (CC BY). The use, distribution or reproduction in other forums is permitted, provided the original author(s) and the copyright owner(s) are credited and that the original publication in this journal is cited, in accordance with accepted academic practice. No use, distribution or reproduction is permitted which does not comply with these terms. 